\title{
Natrium Karbonat : Termodinamika dan Transport Ion
}

\author{
Rima Jumalia ${ }^{1}$, Rahadian Zainul $^{2}$ \\ ${ }^{1}$ Chemistry Education, FMIPA, Universitas Negeri Padang, Indonesia \\ ${ }^{2}$ Physical Chemistry Laboratory, FMIPA, Universitas Negeri Padang, Indonesia \\ ${ }^{\mathbf{1} E m a i l}$ : rimajumalia97@gmail.com \\ ${ }^{2}$ Email : rahadianzmsiphd@yahoo.com
}

\begin{abstract}
Abstrak. Natrium Karbonat merupakan salah satu garam natrium dari asam karbonat yang bersifat higroskospis. Natrium Karbonat biasanya dapat digunakan dalam pembuatan kaca. Sintesis Natrium karbonat dapat dilakukan dengan proses Leblanc dan Solvay. Tujuan dari review ini untuk mengetahui termodinamika dan transport ion pada senyawa natrium karbonat. Metode yang digunakan yaitu studi literatur menggunakan endnote $X 7$, pemodelan komputasi menggunakan ChemOffice 15.0, dan perhitungan matematis. Metode dengan studi literatur dapat dilihat pada fishbone. Metode menggunakan ChemOffice 15.0, pada minimize energy dihasilkan energi $-271.9263 \mathrm{kcal} / \mathrm{mol}$ pada suhu optimum dengan bend nya yaitu 4.4521. Pada metode perhitungan matematis ada beberapa parameter transport ion yang dapat dihitung yaitu konduktivitas, viskositas, mobilitas ion, dan kecepatan hanyut. Parameter ini selain didapatkan dari perhitungan matematis juga dari data hasil review jurnal penelitian yang berkaitan. Hasil perhitungan pada konduktivitas yaitu $0,07905 \times 10^{-8} \mathrm{mho} / \mathrm{cm}$. Nilai viskositas natrium karbonat yaitu $0,313 \times 10^{-3}$ Pa.s. Kelarutan natrium karbonat anhidrat pada suhu $20^{\circ} \mathrm{C}$ yaitu $2.533 \mathrm{~g} / \mathrm{cm}^{3}$. Sifat termokimia pada natrium karbonat ini yaitu $\mathrm{Cp}, \mathrm{S}^{\ominus}, \Delta_{\mathrm{f}} \mathrm{H}^{\ominus}, \Delta_{\mathrm{f}} \mathrm{G}$, masing-masing bernilai 109,2 $\mathrm{J} / \mathrm{mol} \cdot \mathrm{K} ; 136,4 \mathrm{~J} / \mathrm{mol} \cdot \mathrm{K} ;-1131 \mathrm{~kJ} / \mathrm{mol} ;-1047,5 \mathrm{~kJ} / \mathrm{mol}$.

Keyword : Soda abu, mobilitas ion, kecepatan hanyut, solvay.
\end{abstract}

\section{Pendahuluan}

Natrium karbonat adalah garam natrium netral dari asam karbonat yang bersifat higroskopis. Natrium karbonat merupakan salah satu bahan baku paling penting yang digunakan dalam industri kimia dan telah dikenal manusia sejak zaman kuno. Natrium karbonat mempunyai banyak kegunaan diantaranya dalam pembersihan dan pembuatan kaca. Proses produksi bahan alkali natrium karbonat sudah dilakukan dari zaman kuno sampai tahun 1800-an berupa pembakaran vegetasi darat dan air laut yang diikuti oleh proses kalsinasi pada panas $(221 ; 235)$ yang menyala $(238 ; 239)$ dan pencucian abu. Soda abu atau natrium karbonat yang diperoleh dengan cara ini merupakan bahan yang rendah; misalnya, Barilla Spanyol berisi 25 - 30\% natrium karbonat(33-46), Varec dari Normandia 3 - 8\%, dan rumput laut Skotlandia 10 - 15\%. Soda abu diperoleh dari tanaman $(234 ; 241)$ sangat mahal dengan menggunakan proses yang terlalu kuno untuk mendapatkan produk massal dan menghabiskan banyak vegetasi.

Produksi natrium karbonat dalam jumlah besar dilakukan setelah ditemukannya pengembangan proses baru oleh Leblanc pada tahun1742 sampai 1806. Pada tahun 1790, pabrik pertama dibangun di kota Saint-Denis, Prancis. Pada awalnya, produk yang dihasilkan yaitu $300 \mathrm{~kg} / \mathrm{hari}$, kemudian pada tahun-tahun berikutnya industri soda ini berkembang pesat di Inggris. Hal ini terjadi karena meningkatnya permintaan soda abu oleh masyararakat untuk membersihkan kapas dari koloni atau pengotor kapas. Pada pertengahan tahun 1800-an, proses soda abu yang dilakukan oleh Leblanc. 
mengalami persaingan dengan proses Solvay. Diawal tahun 1800-an, penyelidikan dilakukan pada industri tersebut yaitu dilakukannya reaksi dekomposisi ganda antara $\mathrm{NaCl}(47-55)$ dengan $\mathrm{NH}_{4} \mathrm{HCO}_{3}$, namun tidak berhasil. Pada akhirnya Ernest solvay Belgia (1838 - 1932) membawa perkembangan proses Solvay ini ketitik kesuksesan yaitu pada tahun1861 - 1865 .

Pabrik pertama dioperasikan pada tahun 1865 di Couillet, Belgia, dengan produksi awal sebesar 1,5 ton per hari. Pabrik Solvay $(13 ; 14 ; 56)$ pertama di Jerman dibangun pada 1880 di Wyhlen di Rhine bagian atas. Proses Solvay yang secara teknis (231) dan ekonomis telah mampu menggantikan Leblanc, sehingga pada awal tahun 1900-an hanya beberapa dari tanaman Leblanc yang masih diproduksi. Sekitar tahun 1923 Leblanc berhenti beroperasi. Sejak saat itu, proses Solvay lebih mendominasi. Sejak Perang Dunia II, abu soda semakin banyak diperoleh dari trona, terutama di Amerika Serikat.

Proses Leblanc masih di gunakan di Inggris dan benua Eropa selama perang dunia pertama, tetapi jumlahnya terus berkurang selama perang dunia kedua. Pada saat ini proses Leblanc sudah tidak dilakukan lagi karena beberapa kelemahan diantaranya :

1. Konsumsi energi(57-66) yang sangat besar pada saat pelelehan.

2. Membutuhkan tenaga kerja yang intensif karena prosesnya merupakan proses batch yang memerlukan banyak tahap.

3. Menimbulkan dampak lingkungan(67-71).

Karena alasan-alasan di atas tersebut maka pada tahun 1880 proses ini digantikan oleh proses yang lebih bersih dan lebih efisien yaitu proses soda ammonia (proses Solvay). Kemudian pada tahun 1861, Ernest Solvay mulai mengembangkan proses soda ammonia(72-79). Pada mulanya proses ini mengalami kesulitan besar dalam bersaing dengan proses Leblanc yang lebih tua dan lebih mapan, namun dalam beberapa tahun saja proses Solvay berhasil menurunkan harga soda ash sebanyak sepertiganya. Pada tahun 1915 proses soda ammonia akhirnya berhasil menggantikan proses Leblanc.

\section{Metode}

Metode yang digunakan pada review natrium karbonat ini ada tiga macam yaitu studi literatur menggunakan endnote X7, penggambaran molekul dengan aplikasi ChemOffice 15.0, dan perhitungan matematis. Pada metode penggambaran molekul menggunakan aplikasi ChemOffice 15.0, analisis lanjut mengenai $\mathrm{Na}_{2} \mathrm{CO}_{3}$ dilakukan dengan tahapan-tahapan yang dapat dilihat fishbone dibawah. Penelitian dilakukan dengan beberapa tahap, yaitu (1) Analisis 2D molekul $\mathrm{Na}_{2} \mathrm{CO}_{3}$ secara dua dimensi dengan menggunakan ChemDraw 2D, (2) Analisis molekul $\mathrm{Na}_{2} \mathrm{CO}_{3}$ secara 3D menggunakan Chem3D. Pada bagian Chem3D, struktur $\mathrm{Na}_{2} \mathrm{CO}_{3}$ akan berubah menjadi bentuk 3 dimensi dan kemudian dilakukan beberapa analisis sebagai berikut :

1. Menghitung MM2 dari masing-masing molekul yang terdiri atas MM2 minimization, MM2 dynamics dan MM2 properties. Caranya dengan pilih pada bagian calculation, pilih MM2 minimization kemudian pilih minimize energy lalu run. Dengan cara yang sama untuk menentukan molecular dynamics dan compute properties.

2. Analisis Surface Connolly Molecular dengan tipe translucent dan wire wash

3. Analisis (225-229) jarak antara masing-masing atom tiap-tiap, molekul dengan pilih bagian structure, kemudian pilih measurement. 
Pada metode studi literatur menggunakan endnote $X 7$, dapat dilihat pada fishbone berikut :

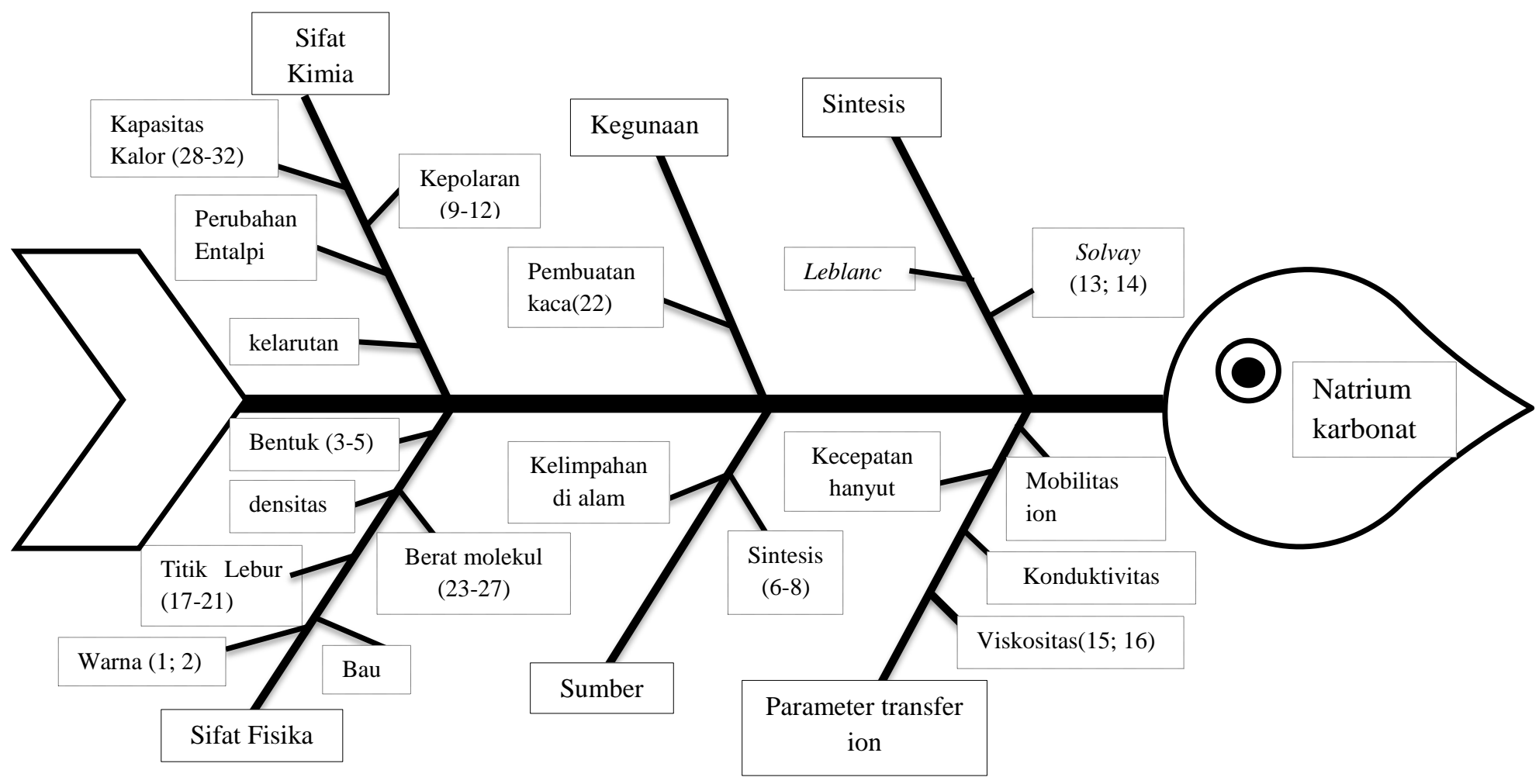

Fishbone Natrium Karbonat

\section{Hasil dan Pembahasan}

\subsection{Sifat Natrium Karbonat}

Natrium karbonat merupakan salah satu garam natrium dari asam (215-217) karbonat yang mudah larut dalam air $(222 ; 223)$. Natrium karbonat yang murni pada umumnya berwarna putih, berupa bubuk tanpa warna yang dapat menyerap embun dari udara, mempunyai rasa yang pahit, dan dapat membentuk larutan alkali(72; 80-90) yang kuat. Dalam karbonat terdapat ikatan kovalen antara karbon dan oksigen.

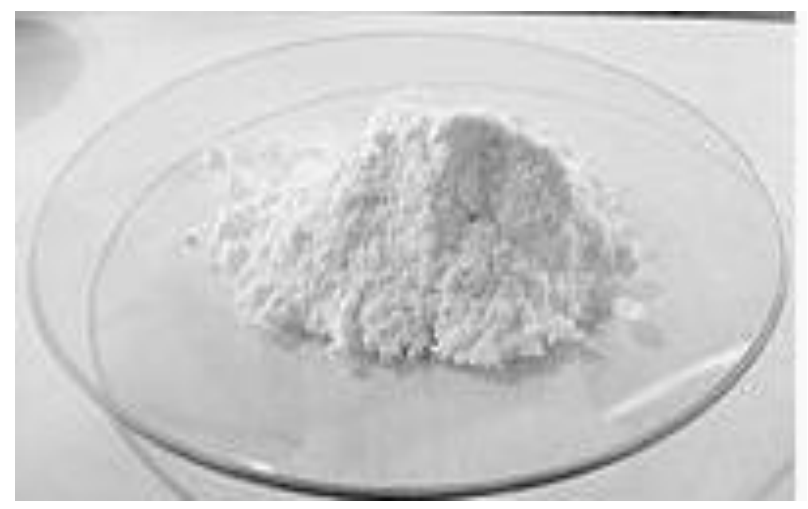

Gambar 1. Natrium Karbonat anhidrat (91) 
Natrium karbonat biasanya terjadi secara alami di daerah (236) kering terutama endapan material (batuan evaporit) yang akan terbentuk ketika danau musiman mengalami penguapan. Endapan(92-95) dari natron telah ditambang dari dasar danau kering di Mesir kuno saat natron digunakan dalam pemurnian dan awal pembuatan kaca.

Tabel 1. Sifat Fisik Natrium Karbonat dan Hidratnya(96)

\begin{tabular}{|c|c|c|c|c|}
\hline & Anhidrat & Monohidrat & Heptahidrat & Dekahidrat \\
\hline Formula & $\mathrm{Na}_{2} \mathrm{CO}_{3}$ & $\mathrm{Na}_{2} \mathrm{CO}_{3} \cdot 6 \mathrm{H}_{2} \mathrm{O}$ & $\mathrm{Na}_{2} \mathrm{CO}_{3} .7 \mathrm{H}_{2} \mathrm{O}$ & $\mathrm{Na}_{2} \mathrm{CO}_{3} \cdot 10 \mathrm{H}_{2} \mathrm{O}$ \\
\hline Mr & 105.99 & 124.00 & 232.10 & 286.14 \\
\hline $\begin{array}{l}\text { Densitas pada } 20^{\circ} \mathrm{C} \\
\left(\mathrm{g} / \mathrm{cm}^{3}\right)\end{array}$ & 2.533 & 2.25 & 1.51 & 1.469 \\
\hline Titik Leleh $\left({ }^{0} \mathrm{C}\right)$ & 851 & $105^{\mathrm{a}}$ & $35.37^{\mathrm{b}}$ & 32.0 \\
\hline Panas fusi $(\mathrm{J} / \mathrm{g})$ & 316 & - & - & - \\
\hline $\begin{array}{l}\text { Kapasitas panas spesifik } \\
\text { at } 25^{\circ} \mathrm{C}\left(\mathrm{J} \mathrm{g} \mathrm{g}^{-1} \mathrm{~K}^{-1}\right)\end{array}$ & 1.043 & 1.265 & 1.864 & 1.877 \\
\hline Panas formasi $(\mathrm{J} / \mathrm{g})$ & 10.676 & - & - & - \\
\hline Panas Hidrasi (J/g) & - & 133.14 & 646.02 & 858.3 \\
\hline Struktur Kristal & Monoklinik & Rombik & $\begin{array}{l}\text { Rombik- } \\
\text { Bipiramidal }\end{array}$ & $\begin{array}{l}\text { Monoklinik- } \\
\text { pseudohexagonal }\end{array}$ \\
\hline Indeks Bias $\left(n_{\alpha} \cdot n_{\beta} \cdot n_{\gamma}\right)$ & $\begin{array}{l}1.410,1.537, \\
1.544\end{array}$ & $\begin{array}{l}1.420,1.506 \\
1.524\end{array}$ & - & $\begin{array}{l}1.405,1.425 \\
1.440\end{array}$ \\
\hline 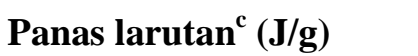 & -222 & -79.6 & 197 & 243 \\
\hline
\end{tabular}

\footnotetext{
${ }^{a}$ dalam air kristal sendiri

${ }^{\mathrm{b}}$ tidak selaras

${ }^{c}$ entalpi terintegrasi larutan pada pengenceran tak terbatas
}

\subsection{Bentuk Molekul}

Natrium karbonat adalah senyawa yang terdiri dari atom $\mathrm{Na}, \mathrm{C}$, dan $\mathrm{O}$. Natrium termasuk golongan IA yang mempunyai 1 elektron(65; 97-104) di kulit terluarnya dan karbon merupakan unsur golongan IVA yang mempunyai 4 elektron di kulit terluarnya, serta oksigen yang merupakan unsur golongan VIA yang mempunyai 6 elektron pada kulit terluarnya. Dalam molekul $(206 ; 207)$ karbonat terdapat ikatan kovalen antara atom karbon dengan oksigen.

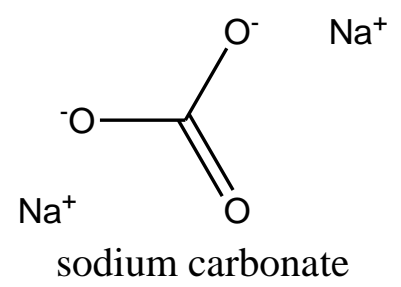

Gambar 2. Molekul $\mathrm{Na}_{2} \mathrm{CO}_{3}$ dalam 2 dimensi (Chemoffice 2D Version 15, Perkinelmer Informatic. Inc, 2015) 


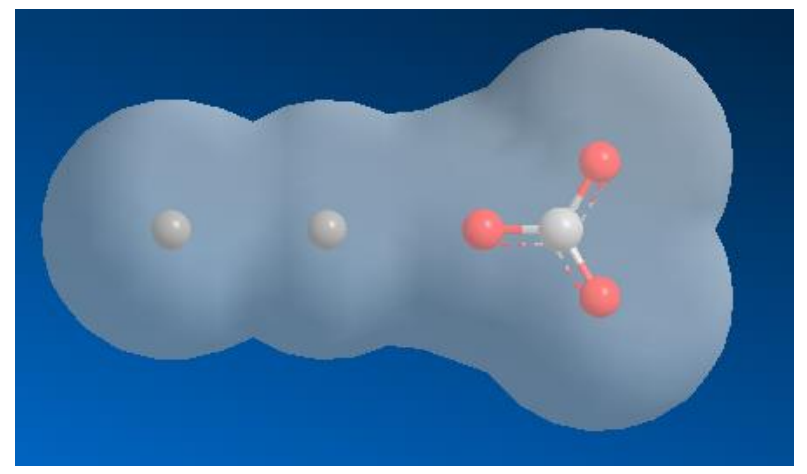

(a)

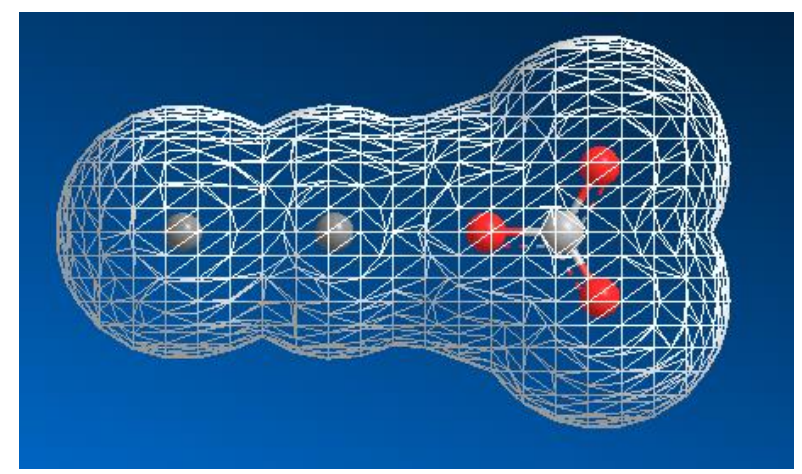

(b)

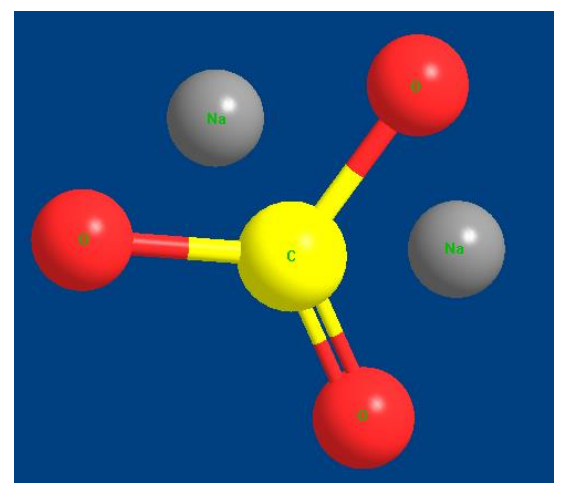

(c)

Gambar 3. Pemodelan Natrium Karbonat dengan Chem3D (a) Struktur Natrium Karbonat dengan Permukaan Translucent, (b) Struktur Natrium karbonat dengan Permukaan Wire Mash, (c) Struktur Natrium Karbonat dalam 3D. (Chemoffice 3D Version 15, Perkinelmer Informatic. Inc, 2015)

\subsection{Sintesis Natrium Karbonat}

Pembuatan natrium karbonat dapat dilakukan dengan dua macam cara yaitu secara alami dan sintetik (230). Secara alami(244) dinamakan proses natural(69; 105-114), sedangkan secara sintetik terdiri dari dua proses yaitu proses Le Blanc dan proses Solvay. Berikut ini penjelasan tentang pembuatan(243) natrium karbonat :

\section{a. Proses Natural}

Bahan baku yang digunakan dalam proses ini yaitu burkeite crystal $\left(\mathrm{Na}_{2} \mathrm{CO}_{3} \cdot 2 \mathrm{Na}_{2} \mathrm{SO}_{4}\right)$ yang sudah dipisahkan dari impuritasnya. Crude burkeite crystal ini terdiri dari $\mathrm{Li}_{2} \mathrm{NaPO}_{4}$ dan $\mathrm{Na}_{2} \mathrm{CO}_{3} \cdot 2 \mathrm{Na}_{2} \mathrm{SO}_{4}$ yang telah dipisahkan, sedangkan filtratnya dipekatkan menjadi $\mathrm{Na}_{2} \mathrm{SO}_{4} \cdot 10 \mathrm{H}_{2} \mathrm{O}$ (garam Glauber's ) (240). Garam Glauber's disaring dan meninggalkan larutan (219) induk yang kaya akan natrium karbonat. Kristal soda yang murni biasanya diperoleh dengan didinginkan dalam tangki pendingin, lalu disaring dan dimasukkan kedalam mesin pengering. Reaksi yang terjadi pada proses ini yaitu:

$$
\mathrm{Na}_{2} \mathrm{CO}_{3} \cdot 2 \mathrm{Na}_{2} \mathrm{SO}_{4(\mathrm{~s})} \rightarrow \mathrm{Na}_{2} \mathrm{CO}_{3(\mathrm{~s})}+2 \mathrm{Na}_{2} \mathrm{SO}_{4(\mathrm{aq})}
$$

Akan tetapi dilihat dari ketersediaan bahan baku, proses natural ini tidak dapat dilakukan di Indonesia karena bahan baku yang dibutuhkan yaitu endapan trona tidak tersedia di Indonesia. Jadi proses yang mungkin dilakukan di Indonesia hanyalah proses Le Blanc dan Solvay. 


\section{b. Proses Leblanc}

Proses Leblanc ini didasarkan pada pemanggangan kerak garam(115-124) dengan karbon dan gamping di dalam tanur putar dan sesudah itu dilakukan proses pengerasan hasilnya dengan air. Produk kasar dari reaksi ini dinamakan black ash (abu hitam). Proses pengerasan biasanya dilakukan pada waktu abu hitam sudah dingin. Saat pengerasan ini berlangsung terjadi hidrolisis sebagian dari sulfida. Hasil hidrolisis ini kemudian diubah lagi menjadi karbonat melalui pengolahan dengan gas(67; 125-132) yang mengandung karbon dioksida $(248 ; 250)$ yang berasal dari tanur abu hitam. Larutan natrium karbonat yang dihasilkan, kemudian dipekatkan sehingga menghasilkan natrium karbonat, lalu dikeringkan atau dikalsinasi. Reaksi yang terjadi dalam proses ini yaitu:

$$
\begin{aligned}
2 \mathrm{NaCl}_{(\mathrm{s})}+\mathrm{H}_{2} \mathrm{SO}_{4(\mathrm{l})} & \Leftrightarrow \mathrm{NaHSO}_{4(\mathrm{~s})}+2 \mathrm{HCl}_{(\mathrm{g})} \\
\mathrm{Na}_{2} \mathrm{SO}_{4(\mathrm{~s})}+4 \mathrm{C}_{(\mathrm{s})} & \Leftrightarrow \mathrm{Na}_{2} \mathrm{~S}_{(\mathrm{s})}+4 \mathrm{CO}_{(\mathrm{g})} \\
\mathrm{Na}_{2} \mathrm{~S}_{(\mathrm{s})}+\mathrm{CaCO}_{3(\mathrm{~s})} & \Leftrightarrow \mathrm{Na}_{2} \mathrm{CO}_{3(\mathrm{~s})}+\mathrm{CaS}_{(\mathrm{s})}
\end{aligned}
$$

\section{c. Proses Solvay (proses soda ammonia)}

Bahan baku yang digunakan pada proses Solvay ini antara lain garam, batu gamping, kokas atau gas bumi dan ammonia yang digunakan sebagai reagen siklus. Keberhasilan dari proses Solvay ini bergantung pada perbandingan ammonia, karbon dioksida dan air(92; 133-138) yang tepat bereaksi membentuk natrium bikarbonat. Ammonium bikarbonat bereaksi dengan natrium klorida membentuk natrium bikarbonat yang relatif tidak larut dalam larutan yang digunakan pada proses Solvay ini. Oleh karena itu larutan $(67 ; 139-145)$ natrium bikarbonat ini dapat disaring dan dipanggang menjadi soda abu. Proses Solvay digunakan dalam hal ini dikarenakan proses Solvay ini lebih ekonomis dan efisien.

Alasan dibawah ini dapat mendukung terlaksananya pembuatan pabrik yang menerapkan proses Solvay, di antaranya yaitu :

1. Bahan baku mudah didapatkan dan murah.

2. Energi yang digunakan relatif kecil

3. Proses yang digunakan lebih efisien karena menggunakan tenaga kerja yang sedikit.

4. Limbah yang dihasilkan tidak berbahaya bagi lingkungan .

5. Dapat diproduksi dalam jumlah yang besar.

\subsection{Karakteristik Atom Penyusun Natrium Karbonat}

\subsubsection{Natrium}

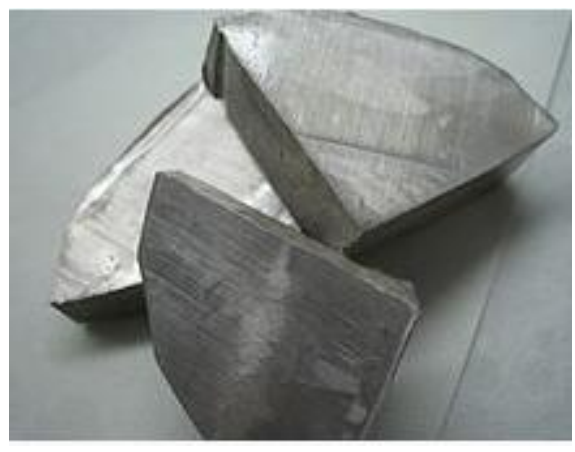

Gambar 4. Logam Natrium(146)

Titik lebur $\quad: 370,87 \mathrm{~K}\left(97,72{ }^{\circ} \mathrm{C}, 207,9^{\circ} \mathrm{F}\right)$

Titik didih $\quad: 1156 \mathrm{~K}\left(883{ }^{\circ} \mathrm{C}, 1621^{\circ} \mathrm{F}\right)$

Jari-jari atom (empiris) : $186 \mathrm{pm}$

Jari-jari kovalen $: 166 \pm 9 \mathrm{pm}$

Jari-jari van der Waals : $227 \mathrm{pm}$ 
Natrium merupakan salah satu unsur kimia dalam tabel periodik yang memiliki lambang Na dan nomor atom 11. Ini adalah salah satu logam (224) lunak, putih keperakan, dan sangat reaktif. Natrium adalah logam alkali, berada pada golongan 1 pada tabel periodik, karena memiliki satu elektron di kulit terluarnya yang mudah disumbangkannya, menciptakan atom bermuatan positif (kation) $\mathrm{Na}^{+}$. Satusatunya isotop stabil adalah ${ }^{23} \mathrm{Na}$. Logam bebasnya tidak terdapat di alam, tapi harus dibuat dari senyawanya(147-156).

\subsubsection{Karbon}

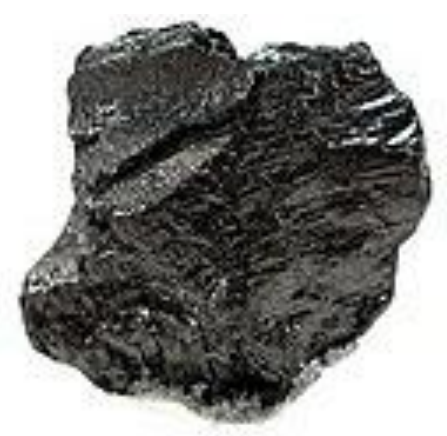

Gambar 5. Karbon (157)

Jari-jari kovalen $\quad: 77\left(\mathrm{sp}^{3}\right), 73\left(\mathrm{sp}^{2}\right), 69(\mathrm{sp}) \mathrm{pm}$

Jari-jari van der Waals : $170 \mathrm{pm}$

Karbon memiliki berbagai bentuk alotrop yang berbeda-beda, meliputi intan yang merupakan bahan terkeras (218) di dunia sampai dengan grafit yang merupakan salah satu bahan terlunak. Karbon juga memiliki afinitas untuk berikatan dengan atom kecil lainnya, sehingga dapat membentuk berbagai senyawa dengan atom(158-166) tersebut. Oleh karenanya, karbon dapat berikatan dengan atom lain (termasuk dengan karbon sendiri) membentuk hampir 10 juta jenis senyawa (208-210) yang berbeda.

\subsubsection{Oksigen}

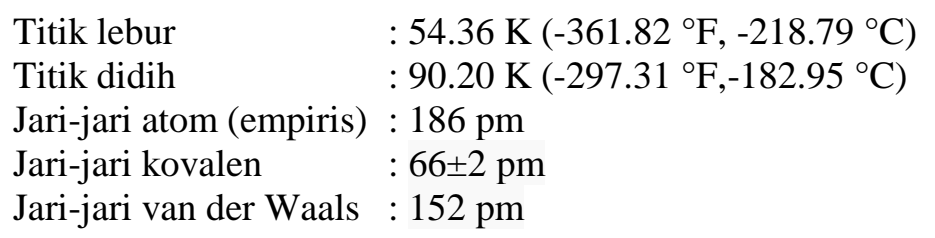

Oksigen merupakan unsur kimia dalam sistem tabel periodik yang mempunyai lambang $\mathrm{O}$ dan nomor atom 8. Oksigen juga merupakan unsur(167-177) golongan kalkogen dan dapat bereaksi dengan hampir semua unsur lainnya dengan mudah dan utamanya menjadi oksida . Pada suhu dan tekanan standar, dua atom oksigen ini dapat berikatan menjadi dioksigen, yaitu senyawa gas diatomik dengan rumus $\mathrm{O}_{2}$ yang memiliki karakteristik seperti, tidak berwarna, tidak berasa, dan tidak berbau. Oksigen(68; 178-186) adalah unsur yang yang kelimpahannya berada pada urutan ketiga di alam semesta berdasarkan massa dan unsur paling melimpah di kerak bumi. 


\subsection{Panjang Ikatan Atom-atom pada Senyawa $\mathrm{Na}_{2} \mathrm{CO}_{3}$}

Tabel 2. Pengukuran panjang ikatan (ChemOffice 15.0)

\begin{tabular}{llll}
\hline No & Atoms & Actual $(\% / A)$ & Optimal $(\% / A)$ \\
\hline $\mathbf{1}$ & $\mathrm{C}(3)-\mathrm{O}(6)$ & 1.250 & 1.250 \\
$\mathbf{2}$ & $\mathrm{C}(3)-\mathrm{O}(5)$ & 1.250 & 1.250 \\
$\mathbf{3}$ & $\mathrm{C}(3)-\mathrm{O}(4)$ & 1.250 & 1.250 \\
$\mathbf{4}$ & $\mathrm{O}(6)-\mathrm{C}(3)-\mathrm{O}(5)$ & 120.000 & 126.000 \\
$\mathbf{5}$ & $\mathrm{O}(6)-\mathrm{C}(3)-\mathrm{O}(4)$ & 120.000 & 126.000 \\
$\mathbf{6}$ & $\mathrm{O}(5)-\mathrm{C}(3)-\mathrm{O}(4)$ & 120.000 & 126.000 \\
$\mathbf{7}$ & $\mathrm{Na}(2)-\mathrm{O}(5)$ & 2.500 & \\
$\mathbf{8}$ & $\mathrm{Na}(1)-\mathrm{Na}(2)$ & 2.500 & \\
\hline
\end{tabular}

\subsection{Optimasi MM2 Natrium Karbonat}

Optimasi molekul $\mathrm{Na}_{2} \mathrm{CO}_{3}$ dilakukan dengan Molecular Mechine (MM2) dan menghasilkan output data dalam bentuk data geometri atom-atom dalam molekul dan energi optimumnya. Hasil output yang diperoleh dapat dilihat sebagai berikut:

a. Minimize Energy

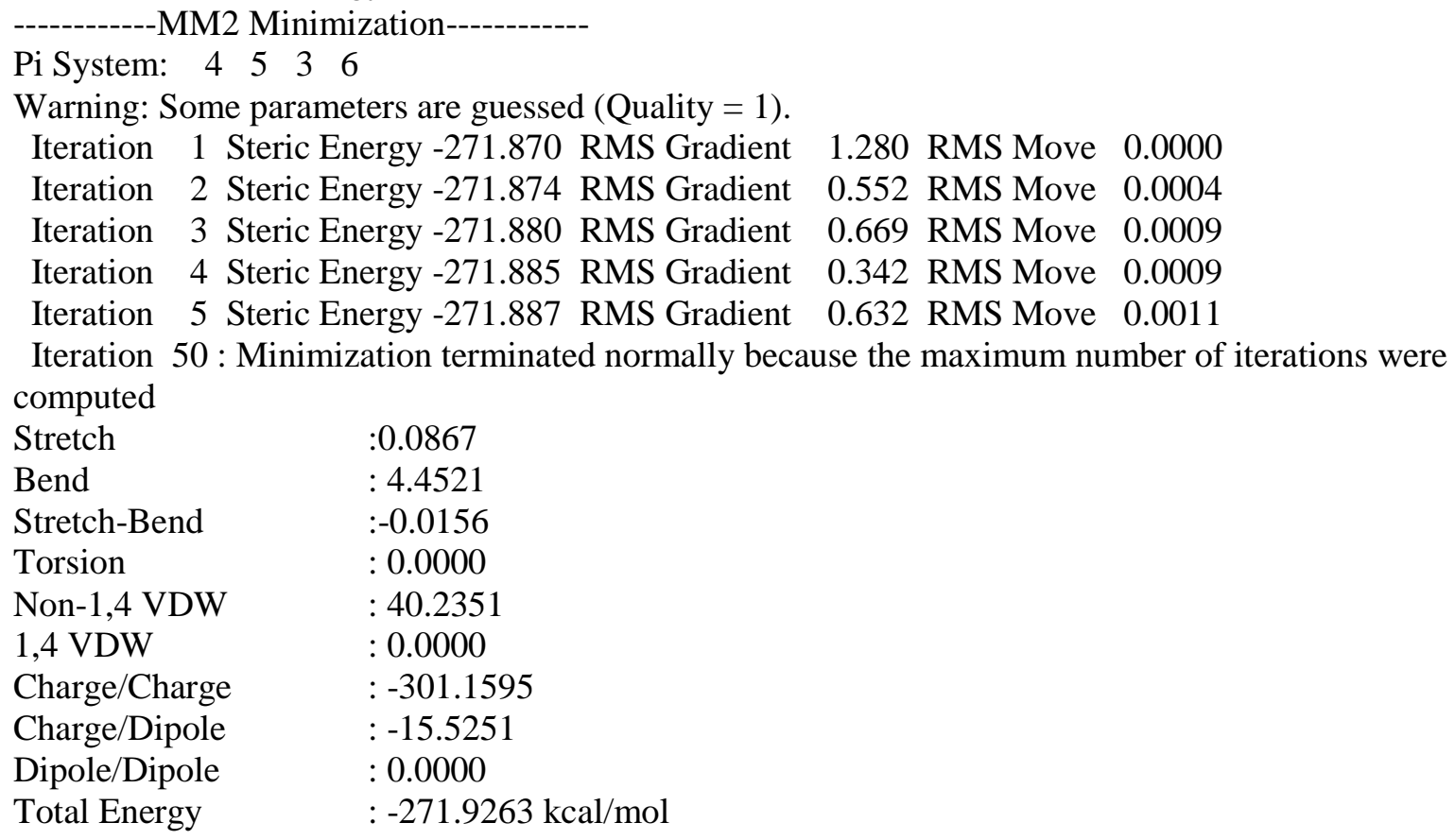

b. Molecular Dynamics -MM2 Dynamics

Pi System: $4 \quad 5 \quad 3 \quad 6$

Warning: Some parameters are guessed (Quality $=1)$.

Iteration Time Total Energy Potential Energy Temperature

$$
\begin{array}{lllllll}
1 & 0.002 & -271.926 \pm & 0.000 & -271.926 \pm 0.000 & 0.00 \pm 0.00 \\
2 & 0.004 & -271.918 \pm & 0.000 & -271.924 \pm 0.000 & 0.35 \pm 0.00 \\
3 & 0.006 & -271.908 \pm 0.000 & -271.920 \pm 0.000 & 0.65 \pm 0.00 \\
4 & 0.008 & -271.901 \pm 0.000 & -271.918 \pm 0.000 & 0.94 \pm 0.00 \\
5 & 0.010 & -271.897 \pm 0.000 & -271.917 \pm 0.000 & 1.15 \pm 0.00
\end{array}
$$

Translational Kinetic Energy: 0.0000 Rotational Kinetic Energy: 0.1698 
c. Compute Properties

$\begin{array}{ll}\text { Pi System } & : 536 \\ \text { Warning } & : \text { Some parameters are guessed (Quality = 1). } \\ \text { Stretch } & : 0.2301 \\ \text { Bend } & : 4.3902 \\ \text { Stretch-Bend } & :-0.0906 \\ \text { Torsion } & : 0.0000 \\ \text { Non-1,4 VDW } & :-0.0954 \\ \text { 1,4 VDW } & : 0.0000 \\ \text { Charge/Charge } & :-302.7020 \\ \text { Charge/Dipole } & :-15.4576 \\ \text { Dipole/Dipole } & : 0.0000 \\ \text { Total Energy } & :-313.7253 \mathrm{kcal} / \mathrm{mol} \\ & :-2.0000 \\ \text { cubic stretch } & : 2.3330 \\ \text { quartic stretch } & : 1.5000 \\ \text { p->dielec } & : 1.5000 \\ \text { p->dieled } & \end{array}$

\begin{tabular}{|c|c|c|c|c|c|c|}
\hline Bond Atoms & Length & $\mathrm{R}(0)$ & Energy & & & \\
\hline $\mathrm{C}(3)-\mathrm{O}(4)$ & 1.250 & 1.250010 .8000 & 0.0000 & & & \\
\hline $\mathrm{C}(3)-\mathrm{O}(5)$ & 1.263 & 1.250010 .8000 & 0.1369 & & & \\
\hline $\mathrm{C}(3)-\mathrm{O}(6)$ & 1.239 & 1.250010 .8000 & 0.0932 & & & \\
\hline Angle Atoms & Theta & TZero & $\mathrm{KB}$ & EB & KSB & ESB \\
\hline $\mathrm{O}(4)-\mathrm{C}(3)-\mathrm{O}(5)$ & 105.460 & 126.0000 & 0.4600 & 4.3117 & 0.12 & -0.0834 \\
\hline $\mathrm{O}(4)-\mathrm{C}(3)-\mathrm{O}(6)$ & 128.263 & 126.0000 & 0.4600 & 0.0652 & 0.12 & -0.0074 \\
\hline $\mathrm{O}(5)-\mathrm{C}(3)-\mathrm{O}(6)$ & 126.210 & 126.0000 & 0.4600 & 0.0134 & 0.12 & 0.0002 \\
\hline
\end{tabular}

\begin{tabular}{|c|c|c|c|c|c|c|c|}
\hline Atoms & Charge & 1 Charge & $2 \mathrm{R}$ & $\mathrm{EC}$ & & & \\
\hline $\mathrm{Na}(1)-\mathrm{Na}(2)$ & 1.000 & 1.000 & 34.2271 & 0.005 & & & \\
\hline $\mathrm{Na}(2)-\mathrm{O}(4)$ & 1.000 & -0.500 & 1.8143 & -61.006 & & & \\
\hline $\mathrm{Na}(2)-\mathrm{O}(4)$ & 1.000 & -0.500 & 1.8143 & -61.006 & & & \\
\hline $\mathrm{Na}(2)-\mathrm{O}(5)$ & 1.000 & -0.500 & 1.8720 & -59.128 & & & \\
\hline $\mathrm{Na}(2)-\mathrm{O}(5)$ & 1.000 & -0.500 & 1.8720 & -59.128 & & & \\
\hline $\mathrm{Na}(2)-\mathrm{O}(6)$ & 1.000 & -0.500 & 3.5453 & -31.220 & & & \\
\hline $\mathrm{Na}(2)-\mathrm{O}(6)$ & 1.000 & -0.500 & 3.5453 & -31.220 & & & \\
\hline Atoms & & Ion & Charge & Dipole & MU & R12(A) & ECD \\
\hline $\mathrm{Na}(2)-\mathrm{O}(4)-\mathrm{C}(3)$ & & $\mathrm{Na}(2)$ & 1.000 & $\mathrm{O}(4)-\mathrm{C}(3)$ & 1.230 & 1.9798 & -5.950 \\
\hline $\mathrm{Na}(2)-\mathrm{O}(5)-\mathrm{C}(3)$ & & $\mathrm{Na}(2)$ & 1.000 & $\mathrm{O}(5)-\mathrm{C}(3)$ & 1.230 & 2.0043 & -5.082 \\
\hline $\mathrm{Na}(2)-\mathrm{O}(4)-\mathrm{C}(3)$ & & $\mathrm{Na}(2)$ & 1.000 & $\mathrm{O}(4)-\mathrm{C}(3)$ & 1.230 & 1.9798 & -5.950 \\
\hline $\mathrm{Na}(2)-\mathrm{O}(5)-\mathrm{C}(3)$ & & $\mathrm{Na}(2)$ & 1.000 & $\mathrm{O}(5)-\mathrm{C}(3)$ & 1.230 & 2.0043 & -5.082 \\
\hline $\mathrm{Na}(2)-\mathrm{O}(6)-\mathrm{C}(3)$ & & $\mathrm{Na}(2)$ & 1.000 & $\mathrm{O}(6)-\mathrm{C}(3)$ & 1.230 & 2.9266 & 6.606 \\
\hline
\end{tabular}

The total energy for this frame: $-313.725 \mathrm{kcal} / \mathrm{mol}$ 


\subsection{Konduktivitas}

Pengukuran dasar yang digunakan untuk mempelajari gerakan ion adalah pengukuran tahanan listrik larutan. Konduktivitas larutan bergantung pada jumlah ion yang ada dan kita biasa memperkenalkan konduktivitas molar $\Lambda \mathbf{m}$, yang didefinisikan sebagai:

$$
\Lambda m=\frac{K}{C}
$$

Konduktivitas molar elektrolit, tidak bergantung pada konsentrasi jika $k$ tepat sebanding dengan konsentrasi. Misalnya konsentrasi ion dalam larutan asam lemah bergantung pada konsentrasi(247) asam secara rumit, dan pendua kalian konsentrasi nomial asam itu tidak mendua-kalikan jumlah tersebut. Kedua karena ion saling berinteraksi dengan kuat sehingga menyebabkan konduktivitas larutan tidak tepat sebanding dengan jumlah ion yang ada. Konduktivitas biasanya tersedia dalam $\mathrm{S} \mathrm{Cm}^{-1}$ dan konsentrasi dalam M. Sehingga hubungan praktisnya adalah :

$$
\begin{gathered}
R=\rho \times \frac{1}{A} \\
k=\frac{1}{R A} \\
\Lambda \mathrm{m}=\frac{100 \times \frac{\mathrm{K}}{\left(\mathrm{s} \mathrm{cm}^{-1}\right) \mathrm{s}} \mathrm{cm}^{2} \mathrm{~mol}^{-1}}{\mathrm{c} / \mathrm{M}}
\end{gathered}
$$

Misalkan terdapat suatu larutan natrium karbonat yang mempunyai massa jenis $2,53 \mathrm{~g} / \mathrm{cm}^{3}$ dalam sebuah wadah yang memiliki panjang $100 \mathrm{~cm}$ dengan luas penampang $100 \mathrm{~cm}^{2}$. Dari data tersebut kita dapat menentukan konduktivitas molar dari larutan natrium karbonat yang mempunyai konsentrasi 5 M, 4 M, 3 M, 2 M, dan 1 M. Hasil perhitungan yang diperoleh dapat dilihat pada tabel dibawah ini.

Tabel 3. Nilai konduktivitas molar $\mathrm{Na}_{2} \mathrm{CO}_{3}$ berdasarkan konsentrasi dalam molaritas

\begin{tabular}{lll}
\hline No & Konsentrasi (mol/L) & Konduktivitas Molar \\
\hline $\mathbf{1}$ & 5 & 0,0079 \\
$\mathbf{2}$ & 4 & 0,009875 \\
$\mathbf{3}$ & 3 & 0,01316 \\
$\mathbf{4}$ & 2 & 0,01975 \\
$\mathbf{5}$ & 1 & 0.0395 \\
\hline
\end{tabular}




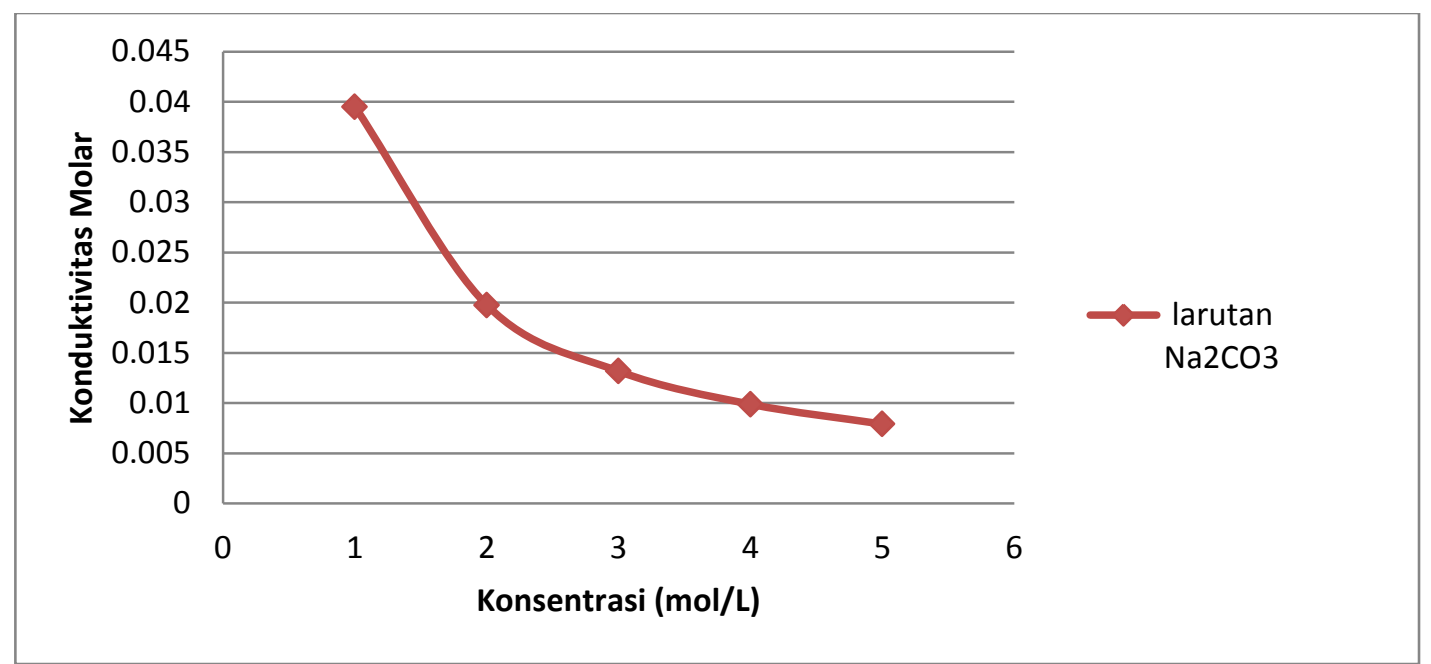

Grafik 1. Hubungan konduktivitas molar terhadap konsentrasi $\mathrm{Na}_{2} \mathrm{CO}_{3}$

Dari tabel dan grafik diatas dapat disimpulkan bahwa semakin besar konsentrasi larutan natrium karbonat maka konduktivitas molarnya semakin kecil.

Jika diketahui $\rho=2,53 \mathrm{~g} / \mathrm{cm}^{3}, l \mathrm{H} 2 \mathrm{O}=5 \times 10^{-8} \mathrm{mho} / \mathrm{cm}$ pada $25^{\circ} \mathrm{C}$ dan luas permukaan air $25 \mathrm{~cm}^{2}$. Tentukan konduktivitas dari ion $\mathrm{Na}_{2} \mathrm{CO}_{3}$ !

$$
\begin{array}{ll}
\mathrm{R}=\rho \times \frac{l}{A} & \mathrm{~K}=\frac{1}{R \times A} \\
R=\frac{2,53 \mathrm{~g}}{c m^{\wedge} 3} \times \frac{5 \times 10^{-8} \mathrm{mho} / \mathrm{cm}}{25 \mathrm{~cm}^{\wedge} \mathrm{C}} & \mathrm{K}=\frac{1}{0,506 \times 10^{-8} \mathrm{mho} \mathrm{g} \mathrm{cm}^{-2} \times 25 \mathrm{~cm}^{2}} \\
\mathrm{R}=0,506 \times 10^{-8} \mathrm{mho} \mathrm{g} \mathrm{cm}^{-2} & \mathrm{~K}=0,07905 \times 10^{-8} \mathrm{mho} / \mathrm{cm}
\end{array}
$$

\subsection{Mobilitas Ion}

Mobilitas ion adalah kecepatan ion pada beda potensial antara kedua elektroda (210-214). Mobilitas ion merupakan perbandingan antara laju dan kuat medan.

$$
\mu=\frac{v}{E}
$$

Mobilitas ion juga dapat dihitung menggunakan pengukuran sebenarnya antara jarak yang di tempuh setiap ion dengan waktu yang diperlukannya untuk menempuh jarak

$$
\mu=\frac{x}{\Delta t}
$$

Mobilitas ion dapat dihitung dengan pengukuran sebenarnya jarak yang ditempuh setiap ion dalam waktu tertentu dengan metode (246) batas bergerak.

$$
\begin{aligned}
& U=\frac{x}{t\left(\frac{d E}{d x}\right)} \\
& E=\frac{d E}{d x}=\frac{I}{A L_{S}}
\end{aligned}
$$


Maka

$$
U=\frac{\lambda_{m}}{z F}
$$

$\mathrm{Z}=$ valensi kation

$\mathrm{F}=$ Faraday

$\mathrm{x}=\operatorname{jarak}(\mathrm{m})$

$\mathrm{t}=$ waktu $(\mathrm{dt})$

$\left(\frac{d E}{d x}\right)=$ kekuatan medan $\left(\right.$ volt. $\left.\mathrm{m}^{-1}\right)$

Tabel 4. Nilai Mobilitas Ionik dalam air pada suhu $298 \mathrm{~K}$

\begin{tabular}{cc}
\hline Ion & Mobilitas Ionik $\left(10^{-8} \mathrm{~m}^{2} \mathrm{~s}^{-1} \mathrm{~V}^{-1}\right)$ \\
\hline $\mathrm{Na}^{+}$ & 5,19 \\
$\mathrm{SO}_{4}{ }^{2-}$ & 8,29 \\
$\mathrm{NO}_{3}{ }^{-}$ & 7,40 \\
\hline
\end{tabular}

\subsection{Kecepatan Hanyut}

Jika ada dua elektroda terpisah dengan jarak t berada pada selisih potensial $\Delta \phi$, maka ion dalam larutan antara kedua elektroda tersebut mempunyai medan listrik yang sama, yaitu:

$$
\mathrm{E}=(\Delta \phi) / \mathrm{t}
$$

Pada keadaan demikian, ion yang bermuatan 2 ze mempunyai gaya sebesar :

$$
\mathrm{Ie}=\mathrm{zeE}=(\mathrm{ze} \Delta \phi) / \mathrm{t}
$$

Kation bereaksi dengan percepatan menuju elektroda negatif dan anion bereaksi dengan percepatan menuju elektroda positif. Akan tetapi, saat ion bergerak melalui pelarut, maka ion akan mengalami gaya gesekan memperlambat Ie' yang sebanding dengan kecepatannya, dan jika diasumsikan maka hukum Stokes untuk bola dengan radius a dan s berlaku pada skala mikroskopis, kita dapat menuliskan gaya perlambatannya sebagai berikut:

$$
\mathrm{Ie}^{\prime}=\mathrm{fsf}=6 \pi \eta \mathrm{a}
$$

Kedua gaya tersebut bekerja pada arah yang berlawanan dan ion mencapai kecepatan akhir yaitu kecepatan hanyut. Jika gaya mempercepat Ie diimbangi oleh penahan kental Ie', maka gaya neto menjadi nol (Ie = Ie' ) dengan syarat:

$$
\mathrm{s}=\mathrm{zeE} / \mathrm{f}
$$

Jika potensial $\mathrm{Na}_{2} \mathrm{CO}_{3}$ adalah $4,0 \mathrm{~V}$ dan jarak antara elektroda adalah $2 \mathrm{~cm}$. Maka, kecepatan hanyutnya dapat dihitung sebagai berikut:

$$
\begin{gathered}
E=\frac{\Delta \phi}{t} \\
E=\frac{4}{2}=2
\end{gathered}
$$




\subsection{Transport Ion}

Fraksi dari arus total yang dibawa oleh ion jenis tertentu yaitu untuk larutan dengan 2 jenis ion bilangan transport kationnya yaitu:

$$
\begin{aligned}
& t_{+}=\frac{I^{+}}{I} \\
& I=t_{+}+t_{-}
\end{aligned}
$$

$\mathrm{I}=$ arus total

Bilangan transport pembatas $\left(\mathrm{t}^{0}\right)$ untuk limit konsentrasi nol dari larutan elektrolit. Jika $I \propto \kappa$, maka :

$$
t^{0}=\frac{z v u}{\sum_{i} z v u_{i}}
$$

Pada elektrolit simetris yaitu bilangan muatan untuk kedua ionnya sama, maka persamaan diatas disederhanakan menjadi:

$$
t^{0}=\frac{u}{\sum_{i} u_{i}}
$$

Hubungan antara konduktivitas ion dengan mobilitas ion :

$$
t^{0}=\frac{v \lambda}{\sum_{i} v_{i} \lambda_{i}}=\frac{v \lambda}{\Lambda_{m}^{0}}
$$

Jadi untuk setiap jenis ion didapatkan:

$$
v \lambda=t^{0} \Lambda_{m}^{0}
$$

Penentuan Bilangan Transport :

1. Metode Hittorf Prinsip $(232 ; 233)$ : Menentukan perubahan konsentrasi elektrolit disekitar elektroda yang disebabkan karena migrasi ion.

2. Metoda perbatasan bergerak

Sel (242) Hittorf : seperangkat alat elektrolisis yang terdiri atas pesawat Hittorf, sepasang elektroda, dan sumber tegangan arus searah

Faktor-f aktor yang mempengaruhi kecepatan ion :

a) Berat dan muatan(187-190) ion semakin ringan ion(129; 191-195) tiap satuan muatan akan semakin cepat ion bergerak.

b) Adanya hidrasi, semakin banyak molekul air yang mengerumuni ion maka akan semakin lambat gerakan ion.

c) Orientasi atmosfer pelarut. 


\subsection{Gaya Termodinamika Gradien Konsentrasi}

Dalam larutan dengan aktivasi partikel $\alpha$, maka potensial kimianya :

$$
\mu=\mu^{\theta}+\mathrm{RT} \ln \alpha
$$

Jika larutan tidak seragam, aktivitas itu bergantung pada posisinya dan kita dapat menuliskan :

$$
\mathrm{Te}=-\mathrm{RT}\left(\frac{\delta \ln a}{\delta x}\right)_{p . \mathrm{T}}
$$

Jika larutan itu ideal, $\alpha$ dapat digantikan dengan kosentrasi $c$, sehingga :

$$
\mathrm{Te}=\frac{-R T}{c}\left(\frac{\delta c}{\delta x}\right) p \cdot \mathrm{T}
$$

\subsection{Hukum Pertama Fick Tentang Difusi}

Andaikan fluks pertikel yang berdifusi, merupakan gerakan sebagai reaksi terhadap gaya termodinamika yang timbul dari gradient konsentrasi. Partikel akan mencapai kecepatan hanyut tetap $s$ jika gaya termodinamika f sama dengan tahan kental.kecepatan hanyut ini sebanding dengan gaya termodinamika, dan kita tuliskan $s \propto$ f. Akan tetapi, fluks partikel $J$ sebanding dengan kecepatan hanyut, dan gaya termodinamika sebanding dengan gradient konsentrasi $d c / d x$.

Rantai kesebandingan itu $(J \propto s, s \propto f$, dan $f \propto d c / d x$ menunjukkan bahwa:

\subsection{Hubungan Einstein}

Hukum Fick untuk fluks partikel dalam mol molekul per satuan luas per satuan waktu adalah:

$$
\mathrm{J}=-\mathrm{D} \frac{d c}{d x}
$$

Dengan D merupakan koefisien difusi dan $d c / d x$ merupakan kemiringan dari konsentrasi molar.

Fluks partikel berhubungan dengan kecepatan hanyut, dengan:

$$
\begin{array}{r}
J=s c \\
J \propto \frac{d c}{d x}
\end{array}
$$

\subsection{Viskositas}

Viskositas merupakan suatu pengukuran dari ketahanan atau kekentalan fluida(63; 199-204) yang diubah pada tekanan maupun tegangan. Dalam kehidupan sehari-hari (hanya untuk fluida), viskositas adalah "Ketebalan" atau "pergesekan internal".

Tabel 4. Viskositas

\begin{tabular}{ll}
\hline Simbol umum & $\underline{\underline{\eta}, \underline{\mu}}$ \\
\hline Satuan SI & $\underline{\mathrm{Pa}} \cdot \underline{\mathrm{s}}=(\underline{\mathrm{N}} \cdot \underline{\mathrm{s}}) / \underline{\mathrm{m}}^{2}=\underline{\mathrm{kg}} /(\underline{\mathrm{s}} \cdot \underline{\mathrm{m}})$ \\
\hline Turunan dari besaran lainnya & $\mu \underline{\mathrm{G}} \cdot \underline{\underline{t}}$ \\
\hline
\end{tabular}


Diketahui : Tegangan permukaan natrium karbonat $0,2046 \mathrm{~N} / \mathrm{m}$. $\rho$ air $=1,00\left(25^{\circ} \mathrm{C}, \mathrm{g} / \mathrm{cm}^{3}\right)$, $\rho \mathrm{Na}_{2} \mathrm{CO}_{3}=2,53\left(25^{\circ} \mathrm{C}, \mathrm{g} / \mathrm{cm}^{3}\right)$.

Ditanya : Berapa besar viskositas dari $\mathrm{Na}_{2} \mathrm{CO}_{3}$ ?

Jawaban :

$$
\begin{aligned}
& \eta=\frac{2 r^{2} g}{9 v}\left(\rho \mathrm{Na}_{2} \mathrm{CO}_{3}-\rho \text { air }\right) \\
& \eta=0,2046 \mathrm{~N} / \mathrm{m}\left(2,53 \times 10^{-3}-1,00 \times 10^{-3}\right) \mathrm{kg} / \mathrm{m}^{3} \\
& \eta=0,2046 \mathrm{~N} / \mathrm{m} \times 1,53 \times 10^{-3} \mathrm{~kg} / \mathrm{m}^{3} \\
& \eta=0,313 \times 10^{-3} \mathrm{~Pa} . \mathrm{s}
\end{aligned}
$$

\subsection{Kegunaan Natrium Karbonat}

Natrium karbonat merupakan salah satu bahan baku penting dalam industri kimia. Kandungan natriumnya menghasilkan sifat peremajaan yang membuatnya penting dalam industri kaca dan silikat. Natrium karbonat atau disebut juga soda abu biasanya digunakan untuk menetralisir asam anorganik dan organik atau garam asam dan untuk menjaga $\mathrm{pH}$ konstan dalam proses(220) di mana asam dibebaskan. Ini juga digunakan dalam produksi garam natrium (misalnya, tartrat, kromat, nitrat, sitrat, fosfat, garam asam lemak).

Natrium karbonat juga dapat digunakan dalam larutan encer untuk menghilangkan sulfur dioksida dari gas proses atau dari gas membentuk natrium sulfit dan natrium bikarbonat :

$$
\begin{aligned}
& \mathrm{Na}_{2} \mathrm{CO}+\mathrm{SO}_{2} \rightarrow \mathrm{Na}_{2} \mathrm{SO}_{3}+\mathrm{CO}_{2} \\
& \mathrm{O}_{2}+\mathrm{Na}_{2} \mathrm{CO}_{3} \rightarrow \mathrm{H}_{2} \mathrm{O}+\mathrm{NaHCO}_{3} \\
& 2 \mathrm{Na}_{2} \mathrm{CO}_{3}+\mathrm{SO}_{2}+\mathrm{H}_{2} \mathrm{O} \rightarrow \mathrm{Na}_{2} \mathrm{SO}_{3}+2 \mathrm{NaHCO}_{3}
\end{aligned}
$$

Reaksi-reaksi diatas juga penting dalam produksi bubur kertas dengan proses sulfit. Kegunaan lain dari natrium karbonat adalah sebagai berikut:

1. Industri kimia: produksi bahan pemutih, boraks, kromat dan dikromat, pupuk, pewarna, pengisi, zat penyamakan, bahan pembersih industri, katalis $(245 ; 249)$, kriolit, perekat, karbonat logam, natrium nitrat, perborat, fosfat, silikat, pigmen ultramarine, silikat terlarut, dll.

2. Industri detergen dan sabun: pembuatan deterjen dan saponifikasi lemak.

3. Petrokimia: netralisasi

4. Industri Pulp dan Kertas: kayu masak; netralisasi, pembersihan, pemutihan, dan perawatan kertas daur ulang.

5. Industri sutra buatan: deacidification dari sutra buatan.

6. Industri tekstil: pencelupan, pemutihan, dan finishing wol dan kapas.

7. Industri besi dan baja: pengangkatan belerang dan fosfor dari besi (251) babi, besi cor, dan baja.

8. Industri logam berat: pencernaan dan benefisiasi bijih (misalnya antimoni, timbal (202-205), krom, kobalt, nikel, bismut, dan timah).

9. Industri makanan(237) : hidrolisis protein, produksi margarin dan pati, dan pelunakan jus bit gula.

10. Perlindungan lingkungan:

-Pemurnian gas buang dengan menyuntikkan natrium karbonat atau natrium hidrogen karbonat (proses kering).

-Regenerasi danau asam oleh pengenalan briket natrium karbonat, sehingga sedimen organik menunjukkan reaksi alkali selama periode panjang. 


\subsection{Toksikologi}

Dosis mematikan paling rendah dari natrium karbonat adalah $4000 \mathrm{mg} / \mathrm{kg}$ (tikus, oral). Efek toksik tidak terjadi dalam kondisi kerja normal. Pada manusia, konsumsi oral apabila massanya lebih dari 15 gram berpotensi mematikan. Dalam kasus menelan, muntah tidak boleh diinduksi, tetapi bisa diatasi dengan minum banyak air dan jus lemon atau cuka dengan takaran dua sendok makan per gelas air. Perut dapat secara hati-hati diirigasi paling banyak selama 15 menit dengan kewaspadaan yang biasa, tetapi penggunaan pengobatan ini untuk periode yang lebih lama sangat kontraindikasi karena reaksi alkalinnya. Natrium karbonat juga memiliki efek iritasi pada kulit dan selaput lendir. Jika terkena bagian kulit, bagian yang terkena harus dicuci bersih dengan air yang banyak, dan pakaian yang tidak mengandung iritasi jika perlu. Jika natrium karbonat terciprat pada mata, kelopak mata harus dipegang terbuka sementara mata dicuci selama beberapa menit dengan air yang mengalir atau dengan menggunakan larutan garam. Setelah itu cari bantuan medis dari seorang spesialis. 


\section{Kesimpulan}

Natrium Karbonat adalah garam natrium dari asam karbonat yang mudah larut dalam air. Natrium karbonat murni mempunyai karakteristik antara lain: berwarna putih, bubuk tanpa warna yang dapat menyerap embun dari udara, mempunyai rasa yang pahit, dan membentuk larutan alkali yang kuat. Natrium Karbonat dapat digunakan dalam pembuatan kaca. Dalam kimia biasanya Natrium karbonat digunakan sebagai elektrolit. Sifat termokimia pada natrium karbonat ini yaitu Cp, $S^{\ominus}, \Delta_{\mathrm{f}} H^{\ominus}, \Delta_{\mathrm{f}} G$, masingmasing bernilai 109,2 J/mol.K ; 136,4 J/mol. K ; $-1131 \mathrm{~kJ} / \mathrm{mol} ;-1047,5 \mathrm{~kJ} / \mathrm{mol}$. Metode menggunakan ChemOffice 15.0, pada minimize energy dihasilkan energi $-271.9263 \mathrm{kcal} / \mathrm{mol}$ pada suhu optimum dengan bend nya yaitu 4.4521. Pada metode perhitungan matematis ada beberapa parameter transport ion yang dapat dihitung yaitu konduktivitas, viskositas, mobilitas ion, dan kecepatan hanyut. Hasil perhitungan pada konduktivitas yaitu $0,07905 \times 10^{-8} \mathrm{mho} / \mathrm{cm}$. Nilai viskositas natrium karbonat yaitu $0,313 \times 10^{-3}$ Pa.s. Kelarutan natrium karbonat anhidrat pada suhu $20^{\circ} \mathrm{C}$ yaitu $2.533 \mathrm{~g} / \mathrm{cm}^{3}$ Dengan menggunakan metode matematis didapatkan grafik hubungan konduktivitas molar dengan konsentrasi, dimana semakin besar konsentrasi larutan natrium karbonat maka konduktivitas molarnya semakin kecil. 


\section{Referensi}

1. Suzuki T, Okada H, Nakagawa T, Komatsu K, Fujimoto C, et al. 2018. A fluorenylidene-acridane that becomes dark in color upon grinding - ground state mechanochromism by conformational change. Chemical science 9:475-82

2. Westfall A, Giusti M. 2017. Color profiles and stability of acylated and nonacylated anthocyanins as novel pigment sources in a lipstick model: A viable alternative to synthetic colorants. Journal of cosmetic science 68:233-44

3. Khalil A, Poelvoorde P, Fayyad-Kazan M, Rousseau A, Nuyens V, et al. 2018. Apoliporotein L3 interferes with endothelial tube formation via regulation of ERK1/2, FAK and Akt signaling pathway. Atherosclerosis 279:73-87

4. Nazaryan-Petersen L, Eisfeldt J, Pettersson M, Lundin J, Nilsson D, et al. 2018. Replicative and non-replicative mechanisms in the formation of clustered CNVs are indicated by whole genome characterization. PLoS genetics 14:e1007780

5. Chen L, Tanimoto A, So BR, Bakhtina M, Magliery TJ, et al. 2018. Stoichiometry of triple-sieve tRNA editing complex ensures fidelity of aminoacyl-tRNA formation. Nucleic acids research

6. Macioszczyk J, Rac-Rumijowska O, Slobodzian P, Teterycz H, Malecha K. 2017. Microfluidical Microwave Reactor for Synthesis of Gold Nanoparticles. Micromachines 8

7. Xie J, Liu L, Xia J, Zhang Y, Li M, et al. 2018. Template-Free Synthesis of Sb2S3 Hollow Microspheres as Anode Materials for Lithium-Ion and Sodium-Ion Batteries. Nano-micro letters 10:12

8. Li J, Xu W, Luo J, Zhou D, Zhang D, et al. 2018. Synthesis of 3D Hexagram-Like CobaltManganese Sulfides Nanosheets Grown on Nickel Foam: A Bifunctional Electrocatalyst for Overall Water Splitting. Nano-micro letters 10:6

9. Ambrozkiewicz MC, Schwark M, Kishimoto-Suga M, Borisova E, Hori K, et al. 2018. Polarity Acquisition in Cortical Neurons Is Driven by Synergistic Action of Sox9-Regulated Wwp1 and Wwp2 E3 Ubiquitin Ligases and Intronic miR-140. Neuron

10. Chen WT, Hsu WT, Yen MH, Changou CA, Han CL, et al. 2018. Alteration of mesenchymal stem cells polarity by laminar shear stimulation promoting beta-catenin nuclear localization. Biomaterials 190-191:1-10

11. Costa Pinto E, Xu C, Cabral LM, Armstrong DW, de Sousa VP. 2018. Sensitive detection of topiramate degradation products by HPLC-ESI-MS using ion-pairing reagents and polarity switching. Rapid communications in mass spectrometry : RCM

12. Li Y, Junge JA, Arnesano C, Gross GG, Miner JH, et al. 2018. Discs large 1 controls daughtercell polarity after cytokinesis in vertebrate morphogenesis. Proceedings of the National Academy of Sciences of the United States of America

13. 2016. Berliner Wissenschaftspreis: P. Hegemann / Clara Immerwahr Award: R. L. Melen / Chemistry for the Future Solvay Prize: B. L. Feringa / Giulio Natta Medal and Lecture Award: K. Kohse-Hoinghaus. Angewandte Chemie 55:2973

14. Sutkowska K, Teper L, Stania M. 2015. Tracing potential soil contamination in the historical Solvay soda ash plant area, Jaworzno, Southern Poland. Environmental monitoring and assessment 187:704

15. Oates RP, Anderson TA, Morse AN, Montagner CC, Klein DM. 2017. Biophysical Viscosity: Thermodynamic Principles of Per Capita Chemical Potentials in Human Populations. ACS omega 2:2878-82

16. Guo Z, Wang W, Gao WS, Gao F, Wang H, Ding WY. 2017. Comparison the clinical outcomes and complications of high-viscosity versus low-viscosity in osteoporotic vertebral compression fractures. Medicine 96:e8936

17. Mei D, Zhang S, Liang F, Zhao S, Jiang J, et al. 2017. LiGaGe2S6: A Chalcogenide with Good Infrared Nonlinear Optical Performance and Low Melting Point. Inorganic chemistry 56:1326773 
18. Matsumoto K, Kimura SI, Iwao Y, Itai S. 2017. Applicability of low-melting-point microcrystalline wax to develop temperature-sensitive formulations. International journal of pharmaceutics 532:528-36

19. Lu J, Obara S, Liu F, Fu W, Zhang W, Kikuchi S. 2018. Melt Extrusion for a High Melting Point Compound with Improved Solubility and Sustained Release. AAPS PharmSciTech 19:358-70

20. Haser A, Huang S, Listro T, White D, Zhang F. 2017. An approach for chemical stability during melt extrusion of a drug substance with a high melting point. International journal of pharmaceutics 524:55-64

21. Chen Z, Greaves TL, Warr GG, Atkin R. 2017. Mixing cations with different alkyl chain lengths markedly depresses the melting point in deep eutectic solvents formed from alkylammonium bromide salts and urea. Chemical communications 53:2375-7

22. Yamashita T, Yasukawa K, Kemmei T, Horii Y, Nakayama E, et al. 2015. Low-cost Methods for Making 3D Fluidic Polymer and Glass Chips Using Metal Templates. Analytical sciences : the international journal of the Japan Society for Analytical Chemistry 31:1261-6

23. Nakamura S, Fouquet T, Sato H. 2018. Molecular Characterization of High Molecular Weight Polyesters by Matrix-Assisted Laser Desorption/Ionization High-Resolution Time-of-Flight Mass Spectrometry Combined with On-plate Alkaline Degradation and Mass Defect Analysis. Journal of the American Society for Mass Spectrometry

24. $\mathrm{Xu} \mathrm{G}$, Yang J, Zhao J. 2018. Molecular weight dependence of chain conformation of strong polyelectrolytes. The Journal of chemical physics 149:163329

25. Bai Y, He J, Zhang Y. 2018. Ultra-High-Molecular-Weight Polymers Produced by the "Immortal" Phosphine-Based Catalyst System. Angewandte Chemie

26. Zhang Y, Zhang X, Yang L, Zhang Q, Fitzgerald ML, et al. 2018. Thermal transport in electrospun vinyl polymer nanofibers: effects of molecular weight and side groups. Soft matter

27. Liu M, Zhang L, Zhao Q, Jiang X, Wu L, Hu Y. 2018. Lower-Molecular-Weight ChitosanTreated Polyethyleneimine: a Practical Strategy For Gene Delivery to Mesenchymal Stem Cells. Cellular physiology and biochemistry : international journal of experimental cellular physiology, biochemistry, and pharmacology 50:1255-69

28. Abramchuk M, Lebedev OI, Hellman O, Bahrami F, Mordvinova NE, et al. 2018. Crystal Chemistry and Phonon Heat Capacity in Quaternary Honeycomb Delafossites: Cu[Li1/3Sn2/3]O2 and $\mathrm{Cu}[\mathrm{Na} 1 / 3 \mathrm{Sn} 2 / 3] \mathrm{O} 2$. Inorganic chemistry 57:12709-17

29. Almeida PF, Carter FE, Kilgour KM, Raymonda MH, Tejada E. 2018. Heat Capacity of DPPC/Cholesterol Mixtures: Comparison of Single Bilayers with Multibilayers and Simulations. Langmuir : the ACS journal of surfaces and colloids 34:9798-809

30. Hidalgo A, Brandolini A, Canadanovic-Brunet J, Cetkovic G, Tumbas Saponjac V. 2018. Microencapsulates and extracts from red beetroot pomace modify antioxidant capacity, heat damage and colour of pseudocereals-enriched einkorn water biscuits. Food chemistry 268:40-8

31. Zhu X, Phinney DM, Paluri S, Heldman DR. 2018. Prediction of Liquid Specific Heat Capacity of Food Lipids. Journal of food science 83:992-7

32. van der Kamp MW, Prentice EJ, Kraakman KL, Connolly M, Mulholland AJ, Arcus VL. 2018. Dynamical origins of heat capacity changes in enzyme-catalysed reactions. Nature communications 9:1177

33. Zhao Y, Cheng G, Xiang Y, Long F, Dong C. 2018. Thermodynamic Study of the Corrosion of Refractories by Sodium Carbonate. Materials 11

34. Sun S, Chen R, Wang G, Wang J. 2018. Sodium carbonate promoted [3 + 2] annulation of alphahalohydroxamates and isocyanates. Organic \& biomolecular chemistry 16:8011-4

35. Braia N, Merabet-Khelassi M, Aribi-Zouioueche L. 2018. Efficient access to both enantiomers of 3-(1-hydroxyethyl)phenol by regioselective and enantioselective CAL-B-catalyzed hydrolysis of diacetate in organic media by sodium carbonate. Chirality 
36. Singh I, Singh A, Kour R, Singh A, Singh R, Bali A. 2018. Is Sodium Carbonate in Snuff a Causative Factor for Oral Mucosal Lesions: A Cross-sectional Analysis. Journal of International Society of Preventive \& Community Dentistry 8:339-42

37. Bouibes A, Takenaka N, Fujie T, Kubota K, Komaba S, Nagaoka M. 2018. Concentration Effect of Fluoroethylene Carbonate on the Formation of Solid Electrolyte Interphase Layer in SodiumIon Batteries. ACS applied materials \& interfaces 10:28525-32

38. Qin J, Wang H, Qin C, Meng H, Qu W, Qian H. 2018. The role of sodium carbonate in PAM coagulation-flocculation for oil acidized wastewater treatment. Water science and technology : a journal of the International Association on Water Pollution Research 77:2677-86

39. Gawkowska D, Cybulska J, Zdunek A. 2018. Cross-linking of sodium carbonate-soluble pectins from apple by zinc ions. Carbohydrate polymers 196:1-7

40. Liu X, Gan J, Nirasawa S, Tatsumi E, Yin L, Cheng Y. 2018. Effects of sodium carbonate and potassium carbonate on colloidal properties and molecular characteristics of konjac glucomannan hydrogels. International journal of biological macromolecules 117:863-9

41. Ozturk B, Serdaroglu M. 2018. Effects of Jerusalem Artichoke Powder and Sodium Carbonate as Phosphate Replacers on the Quality Characteristics of Emulsified Chicken Meatballs. Korean journal for food science of animal resources 38:26-42

42. Lee Y, Lee J, Lee J, Kim K, Cha A, et al. 2018. Fluoroethylene Carbonate-Based Electrolyte with 1 M Sodium Bis(fluorosulfonyl)imide Enables High-Performance Sodium Metal Electrodes. ACS applied materials \& interfaces 10:15270-80

43. Liu J, Xiong H, Tong S, Tang Y, Chen Y, et al. 2018. Hydrogen-motivated electrolysis of sodium carbonate with extremely low cell voltage. Chemical communications 54:3582-5

44. Cai Y, Wang W, Li L, Wang Z, Wang S, et al. 2018. Effective Capture of Carbon Dioxide Using Hydrated Sodium Carbonate Powders. Materials 11

45. Wilson M, Ribeiro MCC, Wilding MC, Benmore C, Weber JKR, et al. 2018. Structure and Liquid Fragility in Sodium Carbonate. The journal of physical chemistry. A 122:1071-6

46. Shen Z, Zhang K, Si M, Liu M, Zhuo S, et al. 2018. Synergy of lignocelluloses pretreatment by sodium carbonate and bacterium to enhance enzymatic hydrolysis of rice straw. Bioresource technology 249:154-60

47. Feng Q, Zhu M, Zhao Y, Liu H, Li M, et al. 2018. Chemical vapor deposition growth of subcentimeter single crystal WSe2 monolayer by NaCl-assistant. Nanotechnology 30:034001

48. Gnedenkov AS, Sinebryukhov SL, Mashtalyar DV, Vyaliy IE, Egorkin VS, Gnedenkov SV. 2018. Corrosion of the Welded Aluminium Alloy in 0.5 M NaCl Solution. Part 2: Coating Protection. Materials 11

49. Gnedenkov AS, Sinebryukhov SL, Mashtalyar DV, Vyaliy IE, Egorkin VS, Gnedenkov SV. 2018. Corrosion of the Welded Aluminium Alloy in $0.5 \mathrm{M} \mathrm{NaCl}$ Solution. Part 1: Specificity of Development. Materials 11

50. Patel LA, Kindt JT. 2018. Simulations of NaCl Aggregation from Solution: Solvent Determines Topography of Free Energy Landscape. Journal of computational chemistry

51. Fukui Y, Miyagawa A, Qu H, Harada M, Okada T. 2018. Growth and Morphology of Liquid Phase in Frozen Aqueous $\mathrm{NaCl}$ Probed by Voltammetry and Simulations. Chemphyschem : $a$ European journal of chemical physics and physical chemistry

52. Zhou QY, Zhao L, Sui XL, Gong XF, Li JZ, et al. 2018. Cobalt and Nitrogen Codoped Carbon Nanosheets Templated from $\mathrm{NaCl}$ as Efficient Oxygen Reduction Electrocatalysts. Chemistry, an Asian journal 13:3057-62

53. Xia K, Tong S, Zhang Y, Tan F, Chen Y, et al. 2018. Heterogeneous Reaction of HCOOH on $\mathrm{NaCl}$ Particles at Different Relative Humidities. The journal of physical chemistry. A 122:721826

54. Javadi S, Royne A. 2018. Adhesive forces between two cleaved calcite surfaces in $\mathrm{NaCl}$ solutions: The importance of ionic strength and normal loading. Journal of colloid and interface science 532:605-13 
55. Zhao CC, Eun JB. 2018. Influence of ultrasound application and $\mathrm{NaCl}$ concentrations on brining kinetics and textural properties of Chinese cabbage. Ultrasonics sonochemistry 49:137-44

56. 2018. Peter J. Dunn Award: B. H. Lipshutz and S. Handa / International Solvay Chair in Chemistry: G. Frenking / Max Born Prize: A. Rubio / Terrae Rarae Prize: R. Kempe / Frontiers in Chemical Energy Science Award: K. Reuter / New Members of the Academia Europaea. Angewandte Chemie 57:2751-2

57. Xue T, Liao SJ, Yang Y, Yan XH, Zou ZL, Luo M. 2018. Nickel induced in situ growth of nickel hydroxide nanoflakes on reduced graphite oxide with high energy and power density. Journal of colloid and interface science 537:50-6

58. Yuan D, Li Y, Li W, Li S. 2018. Structures and properties of large supramolecular coordination complexes predicted with the generalized energy-based fragmentation method. Physical chemistry chemical physics : PCCP

59. Geng C, Vangone A, Folkers GE, Xue LC, Bonvin A. 2018. iSEE: Interface Structure, Evolution and Energy-based machine learning predictor of binding affinity changes upon mutations. Proteins

60. Bina D, Durchan M, Kuznetsova V, Vacha F, Litvin R, Polivka T. 2018. Energy transfer dynamics in a red-shifted violaxanthin-chlorophyll a light-harvesting complex. Biochimica et biophysica acta. Bioenergetics

61. Welch JT, Seeley JP, Cotlet M, Eagleton AM, Higashiya S. 2018. Resonance Energy Transfer in a Genetically Engineered Polypeptide Results in Unanticipated Fluorescence Intensity. Chemistry

62. Lu X, Meng Q, Wang X, Fu B, Zhang DH. 2018. Rate coefficients of the H + H2O2 --> H2 + $\mathrm{HO} 2$ reaction on an accurate fundamental invariant-neural network potential energy surface. The Journal of chemical physics 149:174303

63. Davidchack RL, Laird BB. 2018. Surface free energy of a hard-sphere fluid at curved walls: Deviations from morphometric thermodynamics. The Journal of chemical physics 149:174706

64. Liu T, Fu B, Zhang DH. 2018. Six-dimensional quantum dynamics for the dissociative chemisorption of $\mathrm{HCl}$ on rigid $\mathrm{Ag}(111)$ on three potential energy surfaces with different density functionals. The Journal of chemical physics 149:174702

65. You X, Ramakrishna S, Seideman T. 2018. Unified theory of plasmon-induced resonance energy transfer and hot electron injection processes for enhanced photocurrent efficiency. The Journal of chemical physics 149:174304

66. Eisenbrandt P, Ruckenbauer M, Romer S, Burghardt I. 2018. Gaussian-based multiconfiguration time-dependent Hartree: A two-layer approach. II. Application to vibrational energy transport in a molecular chain. The Journal of chemical physics 149:174101

67. Butcher D, Miksovska J, Ridgeway ME, Park MA, Fernandez-Lima F. 2018. The effects of solution additives and gas-phase modifiers on the molecular environment and conformational space of common heme proteins. Rapid communications in mass spectrometry : RCM

68. Tao H, Bobaker AM, Ramal MM, Yaseen ZM, Hossain MS, Shahid S. 2018. Determination of biochemical oxygen demand and dissolved oxygen for semi-arid river environment: application of soft computing models. Environmental science and pollution research international

69. Lu Y, Dong W, Wang W, Ding J, Wang Q, et al. 2018. Optimal Synthesis of EnvironmentFriendly Iron Red Pigment from Natural Nanostructured Clay Minerals. Nanomaterials 8

70. Maulvault AL, Camacho C, Barbosa V, Alves R, Anacleto P, et al. 2018. Living in a multistressors environment: An integrated biomarker approach to assess the ecotoxicological response of meagre (Argyrosomus regius) to venlafaxine, warming and acidification. Environmental research 169:7-25

71. Nurmi TMA, Kiljunen TK, Knuutinen JS. 2018. A fugacity model assessment of ibuprofen, diclofenac, carbamazepine, and their transformation product concentrations in an aquatic environment. Environmental science and pollution research international

72. Mauksch M, Tsogoeva SB. 2018. Spin-paired solvated electron couples in alkali-ammonia systems. Physical chemistry chemical physics : PCCP 
73. Wang Y, Luo W, Cheng W, Hu M, Wang Q, et al. 2018. Ultrahigh Catalytic Activity of LProline-Functionalized Rh Nanoparticles for Methanolysis of Ammonia Borane. ChemSusChem

74. Mouthier TMB, de Rink B, van Erven G, de Gijsel P, Schols HA, Kabel MA. 2018. Low liquid ammonia treatment of wheat straw increased enzymatic cell wall polysaccharide degradability and decreased residual hydroxycinnamic acids. Bioresource technology 272:288-99

75. Geng C, Li J, Weiske T, Schwarz H. 2018. Ta2 (+)-mediated ammonia synthesis from N2 and H2 at ambient temperature. Proceedings of the National Academy of Sciences of the United States of America

76. Xue X, Chen R, Chen H, Hu Y, Ding Q, et al. 2018. Oxygen Vacancy Engineering Promoted Photocatalytic Ammonia Synthesis on Ultrathin Two-Dimensional Bismuth Oxybromide Nanosheets. Nano letters

77. Kim H, Heo J, Kim J, Baik MH, Chang S. 2018. Copper-Mediated Amination of Aryl C-H Bonds with the Direct Use of Aqueous Ammonia via a Disproportionation Pathway. Journal of the American Chemical Society 140:14350-6

78. Kumarn S, Churinthorn N, Nimpaiboon A, Sriring M, Ho CC, et al. 2018. Investigating the Mechanistic and Structural Role of Lipid Hydrolysis in the Stabilization of Ammonia-Preserved Hevea Rubber Latex. Langmuir : the ACS journal of surfaces and colloids 34:12730-8

79. Fisher OS, Kenney GE, Ross MO, Ro SY, Lemma BE, et al. 2018. Characterization of a long overlooked copper protein from methane- and ammonia-oxidizing bacteria. Nature communications 9:4276

80. Diaz-Rodriguez RM, Robertson KN, Thompson A. 2018. Synthesis and reactivity of aza-dipyrrin alkali metal salts. Chemical communications

81. Chang F, Guan Y, Chang X, Guo J, Wang P, et al. 2018. Alkali and Alkaline Earth HydridesDriven N2 Activation and Transformation over Mn Nitride Catalyst. Journal of the American Chemical Society 140:14799-806

82. Hersbach TJP, McCrum IT, Anastasiadou D, Wever R, Calle-Vallejo F, Koper MTM. 2018. Alkali Metal Cation Effects in Structuring Pt, Rh, and Au Surfaces through Cathodic Corrosion. ACS applied materials \& interfaces

83. Ishiuchi SI, Sasaki Y, Lisy JM, Fujii M. 2018. Ion-peptide interactions between alkali metal ions and a termini-protected dipeptide: modeling a portion of the selectivity filter in $\mathrm{K}(+)$ channels. Physical chemistry chemical physics : PCCP

84. Duerasch A, Wissel J, Henle T. 2018. Reassembling of Alkali-Treated Casein Micelles by Microbial Transglutaminase. Journal of agricultural and food chemistry 66:11748-56

85. Zou W, Guo W, Liu X, Luo Y, Ye Q, et al. 2018. Anion exchange of Ni-Co LDH nanoarrays for a high-capacitance supercapacitor electrode: A comparison of alkali anion exchange and sulfuration. Chemistry

86. Yu Y, Fu Y, Guo X, Yan R, Wang H, et al. 2018. Streptomyces durbertensis sp. nov., isolated from saline-alkali soil. International journal of systematic and evolutionary microbiology 68:3635-40

87. Walz MM, Ghahremanpour MM, van Maaren PJ, van der Spoel D. 2018. Phase-Transferable Force Field for Alkali Halides. Journal of chemical theory and computation 14:5933-48

88. Medvedev AA, Meshkov VV, Stolyarov AV, Heaven MC. 2018. Ab initio interatomic potentials and transport properties of alkali metal $(\mathrm{M}=\mathrm{Rb}$ and $\mathrm{Cs})$-rare gas $(\mathrm{Rg}=\mathrm{He}, \mathrm{Ne}, \mathrm{Ar}, \mathrm{Kr}$, and $\mathrm{Xe})$ media. Physical chemistry chemical physics : PCCP 20:25974-82

89. Yan Z, Shi X, Yu Y, He H. 2018. Alkali resistance promotion of Ce-doped vanadium-titanicbased NH3-SCR catalysts. Journal of environmental sciences 73:155-61

90. Battu S, Itagi M, Manzoor Bhat Z, Khaire S, Kottaichamy AR, et al. 2018. Metal Coordination Polymer Framework Governed by Heat of Hydration for Noninvasive Differentiation of Alkali Metal Series. Analytical chemistry 90:12917-22 
91. Frost RL, Lopez A, Scholz R, Belotti FM, Xi Y. 2015. A vibrational spectroscopic study of the anhydrous phosphate mineral sidorenkite Na3Mn(PO4)(CO3). Spectrochimica acta. Part A, Molecular and biomolecular spectroscopy 137:930-4

92. Adeniji AO, Okoh OO, Okoh AI. 2018. Distribution pattern and health risk assessment of polycyclic aromatic hydrocarbons in the water and sediment of Algoa Bay, South Africa. Environmental geochemistry and health

93. Zhang Z, Zhang C, Huang Z, Yi X, Zeng H, et al. 2018. Residue levels and spatial distribution of phthalate acid esters in water and sediment from urban lakes of Guangzhou, China. Journal of environmental science and health. Part A, Toxic/hazardous substances \& environmental engineering:1-9

94. Ravazzolo D, Mao L, Escauriaza C, Pasten P, Montecinos M. 2018. Rusty river: Effects of tufa precipitation on sediment entrainment in the Estero Morales in the central Chilean Andes. The Science of the total environment 652:822-35

95. Ndunda EN, Madadi VO, Wandiga SO. 2018. Organochlorine pesticide residues in sediment and water from Nairobi River, Kenya: levels, distribution, and ecological risk assessment. Environmental science and pollution research international

96. Tripathy S, Ghole AR, Deep K, Vanjari SRK, Singh SG. 2017. A comprehensive approach for milk adulteration detection using inherent bio-physical properties as 'Universal Markers': Towards a miniaturized adulteration detection platform. Food chemistry 217:756-65

97. Schroeter F, Cisarova I, Soellner J, Herdtweck E, Strassner T. 2018. Electron-poor hemilabile dicationic palladium NHC complexes - synthesis, structure and catalytic activity. Dalton transactions

98. Cheng N, Chen F, Durkan C, Wang N, He Y, Zhao J. 2018. Electron transport behavior of quinoidal heteroacene-based junctions: effective electron-transport pathways and quantum interference. Physical chemistry chemical physics : $P C C P$

99. Grabowski P, Jarosinski P, Szajerski P, Gwardiak H. 2018. Influence of electron beam irradiation on water-saturated biodiesel. Journal of radioanalytical and nuclear chemistry 318:1401-8

100. Rafiq S, Scholes GD. 2018. From Fundamental Theories to Quantum Coherences in Electron Transfer. Journal of the American Chemical Society

101. Wagner RJV, Kruger BC, Park GB, Wallrabe M, Wodtke AM, Schafer T. 2018. Electron transfer mediates vibrational relaxation of $\mathrm{CO}$ in collisions with $\operatorname{Ag}(111)$. Physical chemistry chemical physics : $P C C P$

102. Han HB, Wu ZG, Yan ZP, Zhao Y, Zheng YX. 2018. Efficient green photoluminescence and electroluminescence of iridium complexes with high electron mobility. Dalton transactions

103. Banerjee D, Gupta SK, Patra N, Raja SW, Pathak N, et al. 2018. Unraveling doping induced anatase-rutile phase transition in $\mathrm{TiO} 2$ using electron, $\mathrm{X}$-ray and gamma-ray as spectroscopic probes. Physical chemistry chemical physics : PCCP

104. Shee A, Saue T, Visscher L, Severo Pereira Gomes A. 2018. Equation-of-motion coupled-cluster theory based on the 4-component Dirac-Coulomb(-Gaunt) Hamiltonian. Energies for single electron detachment, attachment, and electronically excited states. The Journal of chemical physics 149:174113

105. Mong KT, Lu YC, Mondal S, Wang CC, Lin CH. 2018. Diverse Synthesis of Natural Trehalosamines and Synthetic 1,1'-Disaccharide Aminoglycosides. Chembiochem : a European journal of chemical biology

106. Hems ES, Wagstaff BA, Saalbach G, Field RA. 2018. Correction: CuAAC click chemistry for the enhanced detection of novel alkyne-based natural product toxins. Chemical communications

107. Nobela O, Renslow RS, Thomas DG, Colby SM, Sitha S, et al. 2018. Efficient discrimination of natural stereoisomers of chicoric acid, an HIV-1 integrase inhibitor. Journal of photochemistry and photobiology. B, Biology 189:258-66

108. Jahan S, Alias YB, Bakar A, Yusoff IB. 2018. Transport and retention behavior of carbonaceous colloids in natural aqueous medium: Impact of water chemistry. Chemosphere 217:213-22 
109. Broda M, Popescu CM. 2018. Natural decay of archaeological oak wood versus artificial degradation processes - An FT-IR spectroscopy and X-ray diffraction study. Spectrochimica acta. Part A, Molecular and biomolecular spectroscopy 209:280-7

110. Dallazen JL, Maria-Ferreira D, da Luz BB, Nascimento AM, Cipriani TR, et al. 2018. Distinct mechanisms underlying local antinociceptive and pronociceptive effects of natural alkylamides from Acmella oleracea compared to synthetic isobutylalkyl amide. Fitoterapia

111. Li H, Jiao R, Mu J, Xu S, Li X, et al. 2018. Bioactive Natural Spirolactone-Type 6,7-seco-entKaurane Diterpenoids and Synthetic Derivatives. Molecules 23

112. Zitoun R, Clearwater SJ, Hassler C, Thompson KJ, Albert A, Sander SG. 2018. Copper toxicity to blue mussel embryos (Mytilus galloprovincialis): The effect of natural dissolved organic matter on copper toxicity in estuarine waters. The Science of the total environment 653:300-14

113. Mossa AH, Mohafrash SMM, Chandrasekaran N. 2018. Safety of Natural Insecticides: Toxic Effects on Experimental Animals. BioMed research international 2018:4308054

114. Geddis SM, Coroama T, Forrest S, Hodgkinson JT, Welch M, Spring DR. 2018. Synthesis and biological evaluation of 1,2-disubsubstituted 4-quinolone analogues of Pseudonocardia sp. natural products. Beilstein journal of organic chemistry 14:2680-8

115. Li B, Zhang D, Li G, Fan J, Chen D, et al. 2018. Heat-treatment assisted molten-salt strategy to enhance electrochemical performances of Li-rich assembled microspheres by tailoring their surface features. Chemistry

116. Zuniga JP, Abdou M, Gupta SK, Mao Y. 2018. Molten-Salt Synthesis of Complex Metal Oxide Nanoparticles. Journal of visualized experiments : JoVE

117. Dadeko AV, Lilge L, Kaspler P, Murav'eva TD, Starodubtcev AM, et al. 2018. Photophysical properties and in vitro photocytotoxicity of disodium salt 2.4-di(alpha-methoxyethyl)deuteroporphyrin-IX (Dimegine). Photodiagnosis and photodynamic therapy

118. Guidi B, Planchestainer M, Contente ML, Laurenzi T, Eberini I, et al. 2018. Strategic single point mutation yields a solvent- and salt-stable transaminase from Virgibacillus sp. in soluble form. Scientific reports 8:16441

119. Eshleman AJ, Nagarajan S, Wolfrum KM, Reed JF, Swanson TL, et al. 2018. Structure-activity relationships of bath salt components: substituted cathinones and benzofurans at biogenic amine transporters. Psychopharmacology

120. Tian L, Li J, Liang F, Chang S, Zhang H, et al. 2018. Facile molten salt synthesis of atomically thin boron nitride nanosheets and their co-catalytic effect on the performance of carbon nitride photocatalyst. Journal of colloid and interface science 536:664-72

121. Jahanbin F, Bozorgmehr MR, Morsali A, Beyramabadi SA. 2018. The effect of different alcohols on the Asp23-Lys28 and Asp23-Ala42 salt bridges of the most effective peptide in Alzheimer's disease: Molecular dynamics viewpoints. Journal of molecular graphics \& modelling 86:199-208

122. Lu Q, Dun J, Chen JM, Liu S, Sun CC. 2018. Improving solid-state properties of berberine chloride through forming a salt cocrystal with citric acid. International journal of pharmaceutics 554:14-20

123. Kumar R, Lokitz B, Long TE, Sumpter BG. 2018. Enhanced scattering induced by electrostatic correlations in concentrated solutions of salt-free dipolar and ionic polymers. The Journal of chemical physics 149:163336

124. Takata N, Tanida S, Nakae S, Shiraki K, Tozuka Y, Ishigai M. 2018. Tofogliflozin Salt Cocrystals with Sodium Acetate and Potassium Acetate. Chemical \& pharmaceutical bulletin 66:1035-40

125. Teng L, Liu Y, Ikram M, Liu Z, Ullah M, et al. 2018. One-step synthesis of palladium oxidefunctionalized tin dioxide nanotubes: Characterization and high nitrogen dioxide gas sensing performance at room temperature. Journal of colloid and interface science 537:79-90

126. Franski R. 2018. Gas phase hydration of polyethylene glycol-metal cation complexes. Journal of mass spectrometry : JMS 
127. Yan Q, Chen L, Liu R, Hao X. 2018. CO2-Cross-Linked Frustrated Lewis Networks as GasRegulated Dynamic Covalent Materials. Angewandte Chemie

128. Diaz de Pool JDN, Van Den Berg SAA, Pilgram GSK, Ballieux B, Van Der Westerlaken LAJ. 2018. Validation of the blood gas analyzer for $\mathrm{pH}$ measurements in IVF culture medium: Prevent suboptimal culture conditions. PloS one 13:e0206707

129. Cunningham EM, Gentleman AS, Beardsmore PW, Mackenzie SR. 2018. Structural isomers and low-lying electronic states of gas-phase $\mathrm{M}(+)(\mathrm{N} 2 \mathrm{O}) \mathrm{n}(\mathrm{M}=\mathrm{Co}, \mathrm{Rh}, \mathrm{Ir})$ ion-molecule complexes. Physical chemistry chemical physics : PCCP

130. Szczesny J, Markovic N, Conzuelo F, Zacarias S, Pereira IAC, et al. 2018. A gas breathing hydrogen/air biofuel cell comprising a redox polymer/hydrogenase-based bioanode. Nature communications 9:4715

131. Pechancova R, Qiu C, Smuts J, Lemr K, Schug KA. 2018. Comparative study of ink photoinitiators in food packages using gas chromatography-vacuum ultraviolet detection and gas chromatography-mass spectrometry. Journal of separation science

132. Matsumoto Y, Ando Y, Hiraoka Y, Tawa A, Ohshimo S. 2018. A Simplified Gas Chromatographic Fatty-Acid Analysis by the Direct Saponification/Methylation Procedure and Its Application on Wild Tuna Larvae. Lipids

133. Zhong Y, Xue F, Wei P, Li R, Cao C, Yi T. 2018. Water-soluble MoS2 quantum dots for facile and sensitive fluorescence sensing of alkaline phosphatase activity in serum and live cells based on the inner filter effect. Nanoscale

134. Zhang S, Zhao Y. 2018. Tuning surface-cross-linking of molecularly imprinted cross-linked micelles for molecular recognition in water. Journal of molecular recognition : JMR:e2769

135. Danil de Namor AFD, Hamdan WA, Webb O, Bance-Soualhi R, Howlin B, Al Hakawati N. 2018. Calix[4]arene urea derivatives: The pathway from fundamental studies to the selective removal of fluorides and phosphates from water. Journal of hazardous materials 364:733-41

136. Ma H, Shen Z, Ben S. 2018. Surfactant-free exfoliation of multilayer molybdenum disulfide nanosheets in water. Journal of colloid and interface science 537:28-33

137. Hofer TS, Wiedemair MJ. 2018. Towards a dissociative SPC-like water model II. The impact of Lennard-Jones and Buckingham non-coulombic forces. Physical chemistry chemical physics : PCCP

138. Ten Hove JB, Schijven LMI, Wang J, Velders AH. 2018. Size-controlled and water-soluble gold nanoparticles using UV-induced ligand exchange and phase transfer. Chemical communications

139. Funes-Ardoiz I, Maseras F. 2018. On the Use of Thermodynamic Cycles for the Calculation of Standard Potentials for the Oxidation of Solid Metals in Solution. Chemphyschem : a European journal of chemical physics and physical chemistry

140. Wang T, Markham A, Thomas SJ, Wang N, Huang L, et al. 2018. Solution Stability of Poloxamer 188 Under stress Conditions. Journal of pharmaceutical sciences

141. Takayanagi T, Becchaku Y, Tomiyama Y, Kurashina M, Mizuguchi H. 2018. Polyethylene Glycols for the Dispersion Development of Graphene in an Aqueous Surfactant Solution Studied by Affinity Capillary Electrophoresis. Analytical sciences : the international journal of the Japan Society for Analytical Chemistry

142. da Silva Porto FG, Campos AD, Garcia ITS. 2018. Distilled pyroligneous liquor obtained from Eucalyptus grandis and chitosan: physicochemical properties of the solution and films. Environmental science and pollution research international

143. Zhou J, Liu L, Pan Y, Zhu Q, Lu Y, et al. 2018. Asymmetric Difluoroboron QuinazolinonePyridine Dyes with Large Stokes Shift: High Emission Efficiencies Both in Solution and in the Solid State. Chemistry

144. Kim Y, Park J. 2018. Colloidal Fluorophore Aggregates for the Selective Detection of Albumins in Solution and on Electrophoresis Gels. Chembiochem : a European journal of chemical biology 
145. Davies JS, Coombes D, Horne CR, Pearce FG, Friemann R, et al. 2018. Functional and solution structure studies of amino sugar deacetylase and deaminase enzymes from Staphylococcus aureus. FEBS letters

146. Zhang Q, Lu Y, Miao L, Zhao Q, Xia K, et al. 2018. An Alternative to Lithium Metal Anodes: Non-dendritic and Highly Reversible Sodium Metal Anodes for Li-Na Hybrid Batteries. Angewandte Chemie 57:14796-800

147. Alhoshani A, Alrashdi A, Alhosaini K, Alanazi FE, Alajez NM, et al. 2018. Gold-containing compound BDG-I inhibits the growth of A549 lung cancer cells through the deregulation of miRNA expression. Saudi pharmaceutical journal : SPJ : the official publication of the Saudi Pharmaceutical Society 26:1035-43

148. Muo IM, Park SJ, Smith A, D AS, Allen MD, et al. 2018. Compound D159687, a phosphodiesterase 4D inhibitor, induces weight and fat mass loss in aged mice without changing lean mass, physical and cognitive function. Biochemical and biophysical research communications

149. Gabardi S, Sosso GG, Behler J, Bernasconi M. 2018. Priming effects in the crystallization of the phase change compound GeTe from atomistic simulations. Faraday discussions

150. Furka A. 2018. Comment on 'Screening and identification of mimotopes of the major shrimp allergen tropomyosin using one-bead-one compound peptide libraries'. Cellular \& molecular immunology

151. Cichorek M, Ronowska A, Gensicka-Kowalewska M, Deptula M, Pelikant-Malecka I, Dzierzbicka K. 2018. Novel therapeutic compound acridine-retrotuftsin action on biological forms of melanoma and neuroblastoma. Journal of cancer research and clinical oncology

152. Shine VJ, Anuja GI, Suja SR, Raj G, Latha PG. 2018. Bioassay guided fractionation of Cyclea peltata using in vitro RAW 264.7 cell culture, antioxidant assays and isolation of bioactive compound tetrandrine. Journal of Ayurveda and integrative medicine

153. Zhu Y, Han Z, Fu L, Liu C, Zhang D. 2018. Cleavage of the beta-O-4 bond in a lignin model compound using the acidic ionic liquid 1-H-3-methylimidazolium chloride as catalyst: a DFT mechanistic study. Journal of molecular modeling 24:322

154. Guo P, Farahat AA, Paul A, Harika NK, Boykin DW, Wilson WD. 2018. Compound Shape Effects in Minor Groove Binding Affinity and Specificity for Mixed Sequence DNA. Journal of the American Chemical Society 140:14761-9

155. Fredenhagen A, Schroer K, Schroder H, Hoepfner D, Ligibel M, et al. 2018. Cladosporin Derivatives Obtained by Biotransformation Provide Guidance for the Focused Derivatization of this Antimalarial Lead Compound. Chembiochem : a European journal of chemical biology

156. Kockerling M, Weiss HD. 2018. A Hexanuclear Niobium Cluster Compound With Intra-Cluster Chelate Ligands: [Nb6(OC2H4NH2)12]I3. Chemistry

157. Zhou M, Wei X, Zhang X, Gao X, Wang X, et al. 2018. Uniform mesoporous carbon hollow microspheres imparted with surface-enriched gold nanoparticles enable fast flow adsorption and catalytic reduction of nitrophenols. Journal of colloid and interface science 537:112-22

158. Jiang J, Saladrigas CA, Erickson TJ, Keenan CL, Field RW. 2018. Probing the predissociated levels of the $\mathrm{S} 1$ state of acetylene via $\mathrm{H}$-atom fluorescence and photofragment fluorescence action spectroscopy. The Journal of chemical physics 149:174309

159. Green SA, Crossley SWM, Matos JLM, Vasquez-Cespedes S, Shevick SL, Shenvi RA. 2018. The High Chemofidelity of Metal-Catalyzed Hydrogen Atom Transfer. Accounts of chemical research

160. Sacramento JJD, Goldberg DP. 2018. Factors Affecting Hydrogen Atom Transfer Reactivity of Metal-Oxo Porphyrinoid Complexes. Accounts of chemical research

161. Marek PH, Urban M, Madura ID. 2018. The study of interactions with a halogen atom: influence of $\mathrm{NH} 2$ group insertion on the crystal structures of meta-bromonitrobenzene derivatives. Acta crystallographica. Section C, Structural chemistry 74:1509-17 
162. Chu J, Carroll TG, Wu G, Telser J, Dobrovetsky R, Menard G. 2018. Probing Hydrogen Atom Transfer at a Phosphorus(V) Oxide Bond Using a "Bulky Hydrogen Atom" Surrogate: Analogies to PCET. Journal of the American Chemical Society

163. Sulbaek Andersen MP, Solling TI, Andersen LL, Volkova A, Hovanessian D, et al. 2018. Atmospheric chemistry of (Z)-CF3CH[double bond, length as m-dash]CHCl: products and mechanisms of the $\mathrm{Cl}$ atom, $\mathrm{OH}$ radical and $\mathrm{O} 3$ reactions, and role of (E)-(Z) isomerization. Physical chemistry chemical physics : PCCP

164. Ribelli TG, Lorandi F, Fantin M, Matyjaszewski K. 2018. Atom Transfer Radical Polymerization: Billion Times More Active Catalysts and New Initiation Systems. Macromolecular rapid communications: 1800616

165. Thirumoorthy K, Karton A, Thimmakondu VS. 2018. From High-Energy C7H2 Isomers with A Planar Tetracoordinate Carbon Atom to An Experimentally Known Carbene. The journal of physical chemistry. A

166. Xia D, Xu W, Wang Y, Yang J, Huang Y, et al. 2018. Enhanced Performance and Conversion Pathway for Catalytic Ozonation of Methyl Mercaptan on Single-Atom Ag Deposited ThreeDimensional Ordered Mesoporous MnO2. Environmental science \& technology

167. Zevenbergen C, Groeneweg S, Swagemakers SMA, de Jong A, Medici-Van den Herik E, et al. 2018. Functional Analysis of Genetic Variation In The Secis Element Of Thyroid Hormone Activating Type 2 Deiodinase. The Journal of clinical endocrinology and metabolism

168. Kondoh H, Toyoshima R, Shirahata N, Hoda A, Yoshida M, et al. 2018. Element selective oxidation on Rh-Pd bimetallic alloy surfaces. Physical chemistry chemical physics : PCCP

169. Evertz M, Kasnatscheew J, Winter M, Nowak S. 2018. Investigation of various layered lithium ion battery cathode materials by plasma- and X-ray-based element analytical techniques. Analytical and bioanalytical chemistry

170. Cook EC, Featherston ER, Showalter SA, Cotruvo JA, Jr. 2018. Structural Basis for Rare Earth Element Recognition by Methylobacterium extorquens Lanmodulin. Biochemistry

171. Bandoniene D, Walkner C, Zettl D, Meisel T. 2018. Rare Earth Element Labeling as a Tool for Assuring the Origin of Eggs and Poultry Products. Journal of agricultural and food chemistry 66:11729-38

172. Novikova M, Adams LJ, Fontana J, Gres AT, Balasubramaniam M, et al. 2018. Identification of a Structural Element in HIV-1 Gag Required for Virus Particle Assembly and Maturation. mBio 9

173. Yari A, Shams A. 2018. Silver-filled MWCNT nanocomposite as a sensing element for voltammetric determination of sulfamethoxazole. Analytica chimica acta 1039:51-8

174. Welty CJ, Sousa ML, Dunnivant FM, Yancey PH. 2018. High-density element concentrations in fish from subtidal to hadal zones of the Pacific Ocean. Heliyon 4:e00840

175. Budko YV, Yampolsky LM, Fedorov YO, Khabarov AA. 2018. The Trace Element Zinc in the Composition of Native Chorionic Gonadotropin. Critical reviews in eukaryotic gene expression 28:337-42

176. Dai Y, Wynn JE, Peralta AN, Sherpa C, Jayaraman B, et al. 2018. Discovery of a Branched Peptide That Recognizes the Rev Response Element (RRE) RNA and Blocks HIV-1 Replication. Journal of medicinal chemistry 61:9611-20

177. Rudolph MJ, Vance DJ, Kelow S, Angalakurthi SK, Nguyen S, et al. 2018. Contribution of an unusual CDR2 element of a single domain antibody in ricin toxin binding affinity and neutralizing activity. Protein engineering, design \& selection : PEDS

178. Chilakala S, Cheng I, Lee I, Xu Y. 2018. Analysis of oxygen-18 labeled phosphate to study positional isotope experiments using LC-QTOF-MS. Analytical biochemistry

179. Lampp L, Rogozhnikova OY, Trukhin DV, Tormyshev VM, Bowman MK, et al. 2018. A radical containing injectable in-situ-oleogel and emulgel for prolonged in-vivo oxygen measurements with CW EPR. Free radical biology \& medicine 130:120-7

180. Epel B, Maggio MC, Barth ED, Miller RC, Pelizzari CA, et al. 2018. Oxygen-guided radiation therapy. International journal of radiation oncology, biology, physics 
181. Gao WK, Chi JQ, Wang ZB, Lin JH, Liu DP, et al. 2018. Optimized bimetallic nickel-iron phosphides with rich defects as enhanced electrocatalysts for oxygen evolution reaction. Journal of colloid and interface science 537:11-9

182. Gil HN, Jung E, Koh D, Lim Y, Lee YH, Shin SY. 2018. A synthetic chalcone derivative, 2hydroxy-3',5,5'-trimethoxychalcone (DK-139), triggers reactive oxygen species-induced apoptosis independently of p53 in A549 lung cancer cells. Chemico-biological interactions

183. Partanen L, Murdachaew G, Laasonen K. 2018. Oxygen Evolution Reaction Kinetic Barriers on Nitrogen-Doped Carbon Nanotubes. The journal of physical chemistry. C, Nanomaterials and interfaces 122:12892-9

184. Yang L, Zhang B, Fang B, Feng L. 2018. A comparative study of NiCo2O4 catalyst supported on $\mathrm{Ni}$ foam and from solution residuals fabricated by a hydrothermal approach for electrochemical oxygen evolution reaction. Chemical communications

185. Shonaka T, Matsuno N, Obara H, Yoshikawa R, Nishikawa Y, et al. 2018. Application of Perfusate With Human-Derived Oxygen Carrier Solution Under Subnormothermic Machine Perfusion for Donation After Cardiac Death Liver Grafts in Pigs. Transplantation proceedings 50:2821-5

186. Xu X, Ding X, Yang X, Wang P, Li S, et al. 2018. Oxygen vacancy boosted photocatalytic decomposition of ciprofloxacin over Bi2MoO6: Oxygen vacancy engineering, biotoxicity evaluation and mechanism study. Journal of hazardous materials 364:691-9

187. Hu J, Wu CX, Ma Y, Tian SX. 2018. Collision-Energy Dependence of the Ion-Molecule Charge Exchange Reaction $\operatorname{Ar}(+)+$ NO. The journal of physical chemistry. A

188. Gadzuk-Shea MM, Bush MF. 2018. Effects of Charge State on the Structures of Serum Albumin Ions in the Gas Phase: Insights from Cation-to-Anion Proton-Transfer Reactions, Ion Mobility, and Mass Spectrometry. The journal of physical chemistry. B 122:9947-55

189. Prehal C, Koczwara C, Amenitsch H, Presser V, Paris O. 2018. Salt concentration and charging velocity determine ion charge storage mechanism in nanoporous supercapacitors. Nature communications 9:4145

190. Randolph CE, Foreman DJ, Betancourt SK, Blanksby SJ, McLuckey SA. 2018. Gas-Phase Ion/Ion Reactions Involving Tris-Phenanthroline Alkaline Earth Metal Complexes as Charge Inversion Reagents for the Identification of Fatty Acids. Analytical chemistry 90:12861-9

191. Saruwatari A, Tamate R, Kokubo H, Watanabe M. 2018. Photohealable ion gels based on the reversible dimerisation of anthracene. Chemical communications

192. Liu T, Lin L, Bi X, Tian L, Yang K, et al. 2018. In situ quantification of interphasial chemistry in Li-ion battery. Nature nanotechnology

193. Dodson LG, Zagorec-Marks W, Xu S, Smith JET, Weber JM. 2018. Intrinsic photophysics of nitrophenolate ions studied by cryogenic ion spectroscopy. Physical chemistry chemical physics : PCCP

194. Mondal AK, Jover J, Ruiz E, Konar S. 2018. Single-ion magnetic anisotropy in a vacant octahedral Co(ii) complex. Dalton transactions

195. Rister AL, Martin TL, Dodds ED. 2018. Application of Group I Metal Adduction to the Separation of Steroids by Traveling Wave Ion Mobility Spectrometry. Journal of the American Society for Mass Spectrometry

196. Akhtar N, Jabeen I, Jalal N, Antilla J. 2018. Structure-Based Pharmacophore Models to Probe Anticancer Activity of Inhibitors of Protein Kinase B-beta (PKB beta). Chemical biology \& drug design

197. Chen Y, Xu W, Zhu H, Wei D, He F, et al. 2018. Effect of turbidity on micropollutant removal and membrane fouling by MIEX/ultrafiltration hybrid process. Chemosphere 216:488-98

198. Yuan T, Yang T, Chen H, Fu D, Hu Y, et al. 2018. New insights into oxidative stress and inflammation during diabetes mellitus-accelerated atherosclerosis. Redox biology 20:247-60 
199. Tsuji A, Yuasa K, Asada C. 2018. Cellulose-binding activity of a 21-kDa endo-ss-1,4-glucanase lacking cellulose-binding domain and its synergy with other cellulases in the digestive fluid of Aplysia kurodai. PloS one 13:e0205915

200. Willemse EAJ, van Maurik IS, Tijms BM, Bouwman FH, Franke A, et al. 2018. Diagnostic performance of Elecsys immunoassays for cerebrospinal fluid Alzheimer's disease biomarkers in a nonacademic, multicenter memory clinic cohort: The ABIDE project. Alzheimer's \& dementia 10:563-72

201. Rubio NC, Bermejo-Barrera P, Bermejo AM, Moreda-Pineiro A. 2018. Development of a Reliable Method for Assessing Coca Alkaloids in Oral Fluid by HPLC-MS-MS. Journal of analytical toxicology

202. Kielbasa A, Krakowska A, Rafinska K, Buszewski B. 2018. Isolation and determination of saponin hydrolysis products from Medicago sativa using supercritical fluid extraction, solid phase extraction and liqiud chromatography with evaporative light scattering detection. Journal of separation science

203. De Vecchi E, Romano CL, De Grandi R, Cappelletti L, Villa F, Drago L. 2018. Alpha defensin, leukocyte esterase, C-reactive protein, and leukocyte count in synovial fluid for pre-operative diagnosis of periprosthetic infection. International journal of immunopathology and pharmacology 32:2058738418806072

204. Krotulski AJ, Mohr ALA, Fogarty MF, Logan BK. 2018. The Detection of Novel Stimulants in Oral Fluid from Users Reporting Ecstasy, Molly and MDMA Ingestion. Journal of analytical toxicology 42:544-53

202. Desy Kurniawati I, Harmiwati SS, Chaidir Z, Munaf E. Rahmiana Zein, Hermansyah Aziz, Rahadian Zainul. 2015. Biosorption of Pb (II) from Aqueous Solutions Using Column Method by Lengkeng (Euphoria logan lour) Seed and Shell. Journal of Chemical and Pharmaceutical Research 7:872-7

203. M., Yani, S. R., \& Zainul, R. (2017, September 4). Aktivasi Tanah Napa dan Pengaruhnya Terhadap Adsorpsi Ion Timbal (II)/ $\mathrm{Pb}_{2+}$. https://doi.org/10.31227/osf.io/ps523

204. M., Sanjaya, H., \& Zainul, R. (2015, December 30). Characterization of napa soil and adsorption of $\mathrm{Pb}$ (II) from aqueous solutions using on column method. https://doi.org/10.31227/osf.io/t8fh9

205. Mawardi Anwar E, Kosela S, Wibowo W, Zainul R. 2015. Study of Pb (II) biosorption from aqueous solution using immobilized Spirogyra subsalsa biomass. Journal of Chemical and Pharmaceutical Research 7:715-22

206. Zainul, R., Oktavia, B., Dewata, I., \& efendi, j. (2017, February 4). Studi Dinamika Molekular dan Kinetika Reaksi pada Pembelahan Molekul Air untuk Produksi Gas Hidrogen. https://doi.org/10.31227/osf.io/876s3

207. Chaidir, z., Fadjria, N., A., \& Zainul, R. (2016, December 5). ISOLATION AND MOLECULAR IDENTIFICATION OF FRESHWATER MICROALGAE IN MANINJAU LAKE WEST SUMATERA. https://doi.org/10.31227/osf.io/nbcuf

208. Iryani, I., Iswendi, I. and Katrina, I. T. (2017) "UJI AKTIVITAS ANTI DIABETES MELLITUS SENYAWA METABOLIT SEKUNDER FRAKSI AIR DARI BERAS KETAN HITAM ( Oryza satival. Var glutinosa) PADA MENCIT PUTIH”, EKSAKTA: Berkala Ilmiah Bidang MIPA, 18(01), pp. 54-60. doi: https://doi.org/10.24036/eksakta/vol18-iss01/17.

209. Sofyanita, S. and Octaria, Z. (2018) "Fenthion Compound Degradation in the Pesticide Bayleton $500 \mathrm{ec}$ in Sonolysis, Ozonolysis and Sonozolysis with Addition of TiO2-anatase", EKSAKTA: Berkala Ilmiah Bidang MIPA, 19(2), pp. 70-79. doi: https://doi.org/10.24036/eksakta/vol19iss $2 / 153$.

210. Suryelita, S., Etika, S. B. and Kurnia, N. S. (2017) "ISOLASI DAN KARAKTERISASI SENYAWA STEROID DARI DAUN CEMARA NATAL (Cupressus funebris Endl.)", EKSAKTA: 
Berkala Ilmiah Bidang MIPA, 18(01), pp. 86-94. doi: https://doi.org/10.24036/eksakta/vol18iss01/23.

211. Zainul, R. (2016, December 18). Design and Modification of Copper Oxide Electrodes for Improving Conversion Coefficient Indoors Lights (PV-Cell) Photocells. https://doi.org/10.31227/osf.io/pgn84

212. H., Sanjaya, H., \& Zainul, R. (2016, August 30). Synthesis and Electrical Properties of ZnO-ITO and Al-ITO thin Film by Spin Coating Technique Through Sol Gel Process. https://doi.org/10.31227/osf.io/unrt4

213. Yasthopi A. 2015. Photoelectrosplitting water for hydrogen production using illumination of indoor lights. Journal of Chemical and Pharmaceutical Research 7:246-56

214. Zainul R, Alif A, Aziz H, Arief S, Dradjad S, Munaf E. 2015. Design of photovoltaic cell with copper oxide electrode by using indoor lights. RESEARCH JOURNAL OF PHARMACEUTICAL BIOLOGICAL AND CHEMICAL SCIENCES 6:353-61

215. Zainul, R. (2016, November 19). Effect of Temperature and Particle Motion against the ability of ZnO Semiconductor Photocatalyst in Humic Acid. https://doi.org/10.31227/osf.io/wnygb

216. Zainul, R. (2016, September 24). Determination of the half-life and the quantum yield of $\mathrm{ZnO}$ semiconductor photocatalyst in humic acid. https://doi.org/10.31227/osf.io/e8a9x

217. Syafei, N., Hidayat, D., Emilliano, E. and Men, L. (2018) "Analysis Cracking Corrosion on Carbon Steel Pipes API 5L-X65 In Solution $7700 \mathrm{ml}$ Aquades, $250 \mathrm{ml}$ Acetic Acid and $50 \mathrm{ml}$ Ammonia with Gas CO2 and H2S in Saturation Condition", EKSAKTA: Berkala Ilmiah Bidang MIPA, 19(2), pp. 21-31. doi: https://doi.org/10.24036/eksakta/vol19-iss2/138.

218. Febriani, S. S., Yolanda, T., Arianti, V. A., \& Zainul, R. (2018, September 2). A Review Solid Stated : Principles and Methode. https://doi.org/10.31227/osf.io/7us4x

219. Liza, Y. M., Yasin, R. C., Maidani, S. S., \& Zainul, R. (2018, September 29). SOL GEL : PRINCIPLE AND TECHNIQUE (A REVIEW). https://doi.org/10.31227/osf.io/2cuh8

220. Dinata, A. A., Rosyadi, A. M., Hamid, S., \& Zainul, R. (2018, August 31). A Review CHEMICAL VAPOR DEPOSITION : PROCESS AND APPLICATION. https://doi.org/10.31227/osf.io/yfeau

221. Putri, D. F., Ritonga, H. M., Murdiati, V., \& Zainul, R. (2018, August 31). A REVIEW WHAT IS HYDROTHERMAL ?. https://doi.org/10.31227/osf.io/dm56c

222. Zainul R, Dewata I. 2015. Determination of $\mathrm{pH}-\mathrm{BOD}-\mathrm{COD}$ and degradation in batang arau watersheds at Padang city. 10.31227/osf.io/efdzj

223. Dinata, M. and Soehardi, F. (2018) "Factor Analysis of Physics Chemistry Waters that Affects Damage Safety Cliff on the Outskirts of River Siak", EKSAKTA: Berkala Ilmiah Bidang MIPA, 19(2), pp. 46-49. doi: https://doi.org/10.24036/eksakta/vol19-iss2/143.

224. Harahap, F. and Lubis, L. (2018) "Analysis of Heavy Metals Distribution in the River Town of Hamasaki’s Rod Padangsidimpuan”, EKSAKTA: Berkala Ilmiah Bidang MIPA, 19(2), pp. 50-56. doi: https://doi.org/10.24036/eksakta/vol19-iss2/149.

225. Ramli, R., Jonuarti, R. and Hartono, A. (2017) “ANALISIS STRUKTUR NANO DARI LAPISAN TIPIS COBALT FERRITE YANG DIPREPARASI DENGAN METODE SPUTTERING", EKSAKTA: Berkala Ilmiah Bidang MIPA, 18(01), pp. 46-53. doi: https://doi.org/10.24036/eksakta/vol18-iss01/16.

226. Saiya, A. (2017) “ANALISIS RESIDU KLORPIRIFOS DALAM SAYURAN KUBIS DENGAN METODE HPLC DI BEBERAPA PASAR TRADISIONAL DI SULAWESI UTARA", EKSAKTA: Berkala Ilmiah Bidang MIPA, 18(02), pp. 77-85. doi: https://doi.org/10.24036/eksakta/vol18-iss02/57.

227. Syafei, N. (2017) “ANALISA FENOMENA KOROSI PELAT PIPA BAJA KARBON API 5LX65 DALAM LARUTAN 250 ML ASAM ASETAT DAN 4750 ML AQUADES PADA KONDISI GAS CO2 DAN H2S JENUH PADA SUHU RUANG”, EKSAKTA: Berkala Ilmiah Bidang MIPA, 18(02), pp. 113-120. doi: https://doi.org/10.24036/eksakta/vol18-iss02/63.

228. Syafei, N. (2018) "Riset Material ANALISA FENOMENA KOROSI PELAT PIPA BAJA KARBON API 5L-X65 DALAM LARUTAN 7900 ML AIR LAUT DAN 100 ML AMONIAK 
PADA KONDISI GAS CO2 DAN H2S JENUH PADA SUHU RUANG.”, EKSAKTA: Berkala Ilmiah Bidang MIPA, 19(1), pp. 7-13. doi: https://doi.org/10.24036/eksakta/vol19-iss1/83.

229. Parbuntari, H., Prestica, Y., Gunawan, R., Nurman, M. and Adella, F. (2018) "Preliminary Phytochemical Screening (Qualitative Analysis) of Cacao Leaves (Theobroma cacao L.)", EKSAKTA: Berkala Ilmiah Bidang MIPA, 19(2), pp. 40-45. doi: https://doi.org/10.24036/eksakta/vol19-iss2/142.

230. Awalliyah, A., Ikhwan, H., Nugiasari, V., \& Zainul, R. (2018, August 31). A REVIEW PRINSIP DASAR MILLING DALAM SINTESIS MATERIAL. https://doi.org/10.31227/osf.io/9xsqe

231. Candani, D., Ulfah, M., Noviana, W., \& Zainul, R. (2018, September 1). A Review Pemanfaatan Teknologi Sonikasi. https://doi.org/10.31227/osf.io/uxknv

232. Fatimah, P., Jumalia, R., Novianti, E. R., \& Zainul, R. (2018, August 31). A REVIEW Teknik Blended : Prinsip dan Dasar-Dasar. https://doi.org/10.31227/osf.io/tm2w4

233. P, O. M., A, L. G., S, A. Y. M., \& Zainul, R. (2018, September 1). A Review Grinding : Teknik dan Prinsip Dasar pada Pengolahan Material. https://doi.org/10.31227/osf.io/trv4q

234. chaidir, z., Zainul, R., Nurakhbari, D., \& Salim, M. (2016, September 24). Optimization of Spirulina Platensis Culture for Antioxidant Production. https://doi.org/10.17605/OSF.IO/FD6E4

235. Zainul R, Oktavia B, Dewata I, Efendi J. Thermal and Surface Evaluation on The Process of Forming a $\mathrm{Cu} 2 \mathrm{O} / \mathrm{CuO}$ Semiconductor Photocatalyst on a Thin Copper Plate. Proc. IOP Conference Series: Materials Science and Engineering, 2018, 335:012039: IOP Publishing

236. Mawardi M, Deyundha D, Zainul R. Characterization of PCC Cement by Addition of Napa Soil from Subdistrict Sarilamak 50 Kota District as Alternative Additional Material for Semen Padang. Proc. IOP Conference Series: Materials Science and Engineering, 2018, 335:012034: IOP Publishing

237. Anhar A, Sumarmin R, Zainul R. 2016. Measurement of Glycemic Index of West Sumatera Local Rice Genotypes for Healthy Food Selection. https://doi.org/10.31227/osf.io/tgy8h

238. Zainul R, Alif A, Aziz H, Arief S. 2015. DISAIN GEOMETRI REAKTOR FOTOSEL CAHAYA RUANG. Jurnal Riset Kimia 8:131 https://doi.org/10.25077/jrk.v8i2.230

239. Zainul R. 2015. Disain dan Modifikasi Kolektor dan Reflektor Cahaya pada Panel Sel Surya $\mathrm{Al} / \mathrm{Cu} 2 \mathrm{O}-\mathrm{Gel} \mathrm{Na} 2 \mathrm{SO} 4$. . http://repository.unp.ac.id/id/eprint/610

240. Zainul R, Alif A, Aziz H, Arief S, Darajat S. 2015. Modifikasi dan Karakteristik IV Sel Fotovoltaik $\mathrm{Cu} 2 \mathrm{o} / \mathrm{Cu}-\mathrm{Gel} \mathrm{Na} 2 \mathrm{so} 4$ Melalui Iluminasi Lampu Neon. EKSAKTA 2:50

241. Chaidir, z., Zainul, R., Nurakhbari, D., \& Salim, M. (2016, September 24). Optimization of Spirulina Platensis Culture for Antioxidant Production. https://doi.org/10.17605/OSF.IO/FD6E4

242. Zainul, R., \& Prima, C. B. (2017, June 29). Desain Geometri Sel PV. https://doi.org/10.31227/osf.io/7n8t4

243. Horiza, H., Azhar, M. and Efendi, J. (2017) "EKSTRAKSI DAN KARAKTERISASI INULIN DARI UMBI DAHLIA (Dahlia sp.L) SEGAR DAN DISIMPAN", EKSAKTA: Berkala Ilmiah Bidang MIPA, 18(01), pp. 31-39. doi: https://doi.org/10.24036/eksakta/vol18-iss01/14.

244. Iskandar, I., Horiza, H. and Fauzi, N. (2017) "EFEKTIVITAS BUBUK BIJI PEPAYA (Carica Papaya Linnaeaus) SEBAGAI LARVASIDA ALAMI TERHADAP KEMATIAN LARVA AEDES AEGYPTY TAHUN 2015”, EKSAKTA: Berkala Ilmiah Bidang MIPA, 18(01), pp. 12-18. doi: https://doi.org/10.24036/eksakta/vol18-iss01/12.

245. Sanjaya, H. (2017) "DEGRADASI METHYLENE BLUE MENGGUNAKAN KATALIS ZnOPEG DENGAN METODE FOTOSONOLISIS”, EKSAKTA: Berkala Ilmiah Bidang MIPA, 18(02), pp. 21-29. doi: https://doi.org/10.24036/eksakta/vol18-iss02/45.

246. Ningsih, S. K. (2017) "SINTESIS DAN KARAKTERISASI NANOPARTIKEL ZnO DOPED Cu2+ MELALUI METODA SOL-GEL”, EKSAKTA: Berkala Ilmiah Bidang MIPA, 18(02), pp. 39-51. doi: https://doi.org/10.24036/eksakta/vol18-iss02/51.

247. Tutuarima, T. (2017) "SIFAT FISIK DAN KIMIA MARMALADE JERUK KALAMANSI (Citrus microcarpa) : KAJIAN KONSENTRASI PEKTIN DAN SUKROSA Physical and Chemical Properties of Marmalade Citrus of Calamondin (Citrus microcarpa) : Study of Pectin and Sucrose 
Concentrations", EKSAKTA: Berkala Ilmiah Bidang MIPA, 18(02), pp. 164-172. doi: https://doi.org/10.24036/eksakta/vol18-iss02/73.

248. Ruswandi, R. (2018) "Determination of Fructose Content resulted by Inulin Hydrolysis with DNS as Oxidizer", EKSAKTA: Berkala Ilmiah Bidang MIPA, 19(1), pp. 14-23. doi: https://doi.org/10.24036/eksakta/vol19-iss1/102.

249. Sanjaya, H. (2018) "DEGRADASI METIL VIOLET MENGGUNAKAN KATALIS ZnO-TiO2 SECARA FOTOSONOLISIS", EKSAKTA: Berkala Ilmiah Bidang MIPA, 19(1), pp. 91-99. doi: https://doi.org/10.24036/eksakta/vol19-iss1/131.

250. Hidayani, T. (2018) "GRAFTING POLIPROPILENA DENGAN MALEAT ANHIDRIDA SEBAGAI PENGIKAT SILANG DENGAN INISIATOR BENZOIL PEROKSIDA”, EKSAKTA: Berkala Ilmiah Bidang MIPA, 19(1), pp. 56-62. doi: https://doi.org/10.24036/eksakta/vol19iss $1 / 127$.

251. Prabowo, H. (2018) "PENYELIDIKAN KELAYAKAN KIMIA DAN PENYEBARAN CADANGAN PASIR BESI DAERAH TIKU KABUPATEN AGAM UNTUK BAHAN BAKU SEMEN PADA PT. SEMEN PADANG", EKSAKTA: Berkala Ilmiah Bidang MIPA, 19(1), pp. 3942. doi: https://doi.org/10.24036/eksakta/vol19-iss1/121. 